\title{
Letting Girls Play: The Mathare Youth Sports Association's football program for girls
}

Martha Brady

Population Council

Arjmand Banu Khan

Follow this and additional works at: https://knowledgecommons.popcouncil.org/departments_sbsr-pgy

Part of the Family, Life Course, and Society Commons How does access to this work benefit you? Let us know!

\section{Recommended Citation}

Brady, Martha and Arjmand Banu Khan. 2002. "Letting girls play: The Mathare Youth Sports Association's football program for girls." New York: Population Council. 


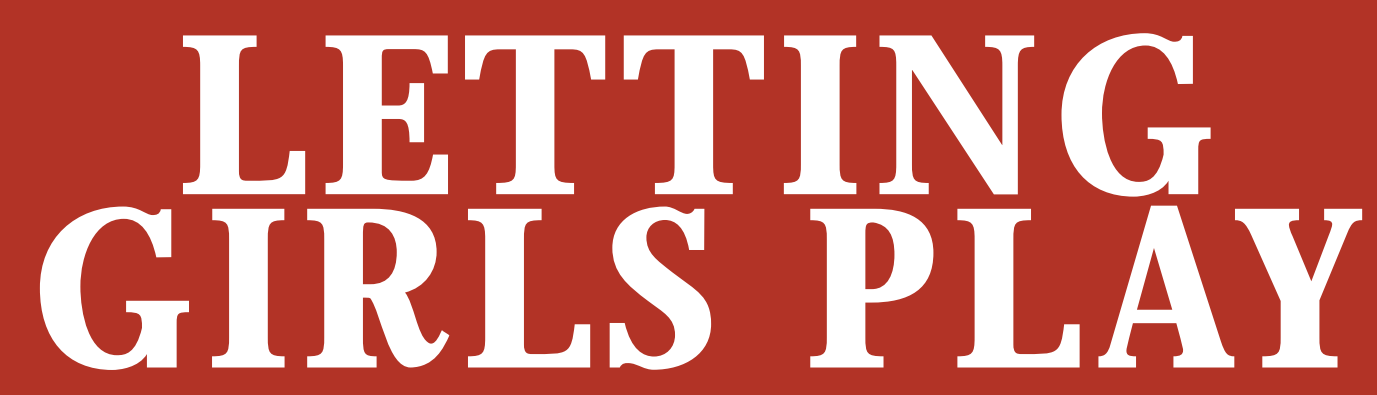

THE MATHARE YOUTH SPORTS ASSOCIATION'S FOOTBALL PROGRAM FOR GIRLS

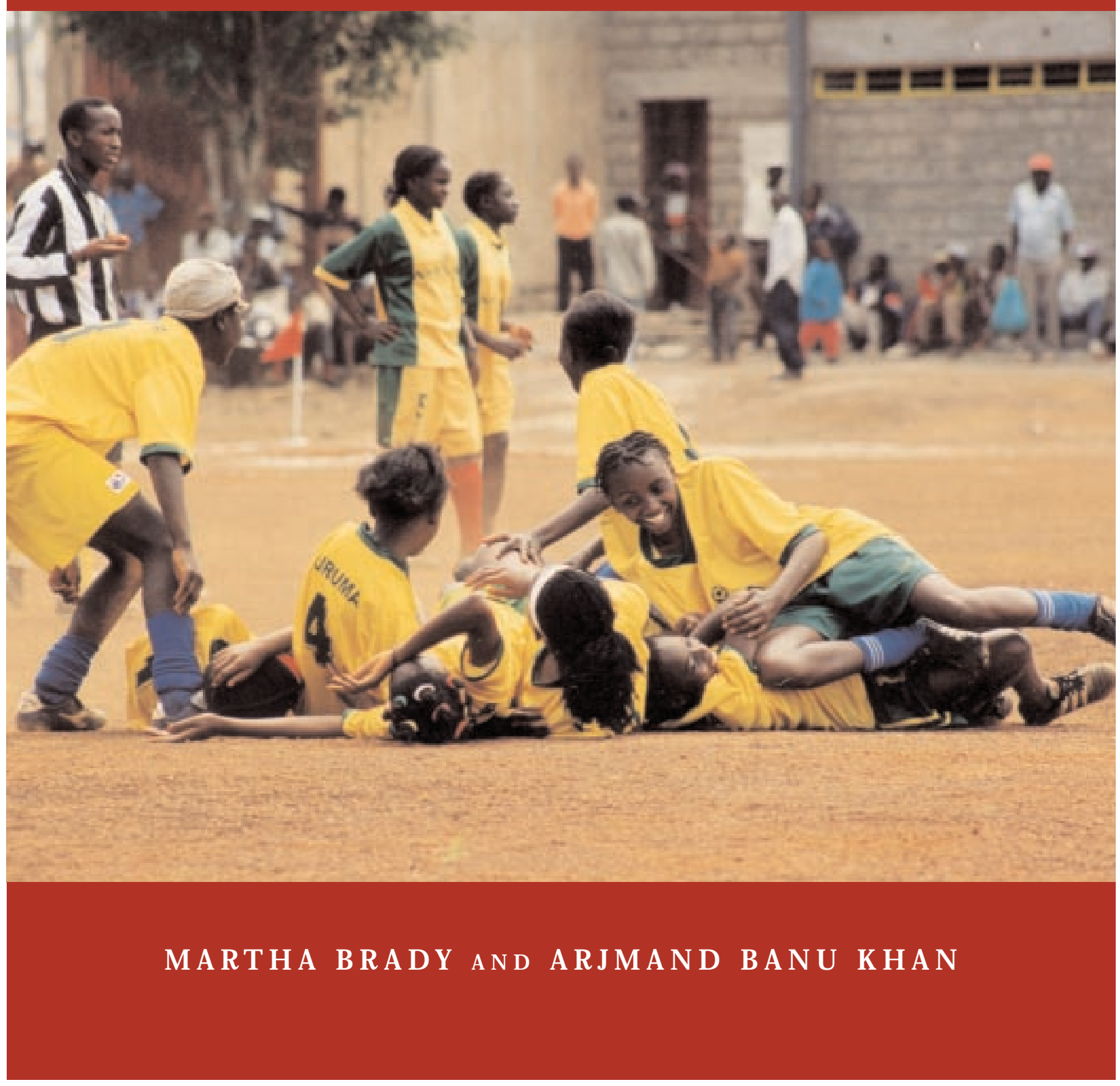




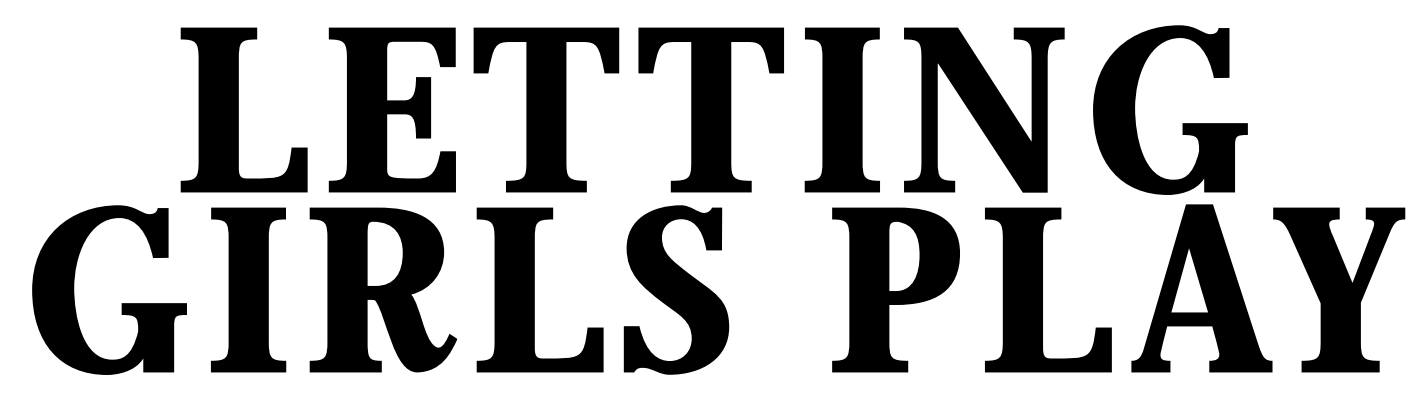

THE MATHARE YOUTH SPORTS ASSOCIATION'S FOOTBALL PROGRAM FOR GIRLS

MARTHA BRADY AND ARJMAND BANU KHAN

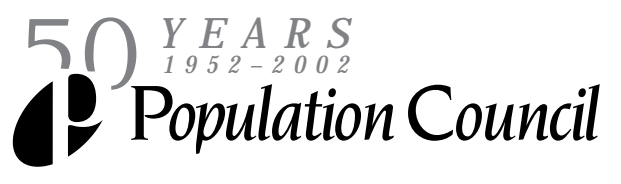




\section{PP Population Council}

O ne D ag $\mathrm{H}$ ammarskjold Plaza

N ew York, N ew York 10017

telephone: 001 212-339-0500

fax: 001 212-755-6052

e-mail: pubinfo@popcouncil.org

www.popcouncil.org

The Population Council is an international, nonprofit, nongovernmental organization that seeks to improve the well-being and reproductive health of current and future generations around the world and to help achieve a humane, equitable, and sustainable balance between people and resources. The C ouncil conducts biomedical, social science, and public health research and helps build research capacities in developing countries. Established in 1952, the Council is governed by an international board of trustees. Its N ew York headquarters supports a global network of regional and country offices.

(c) 2002 by The Population Council, Inc.

M artha Brady is a program associate with the Gender, Family, and D evelopment program, Population Council, N ew York.

Arjmand Banu Khan is a program officer with the G ender, Family, and D evelopment program, Population Council, Nairobi, Kenya.

Any part of this publication may be photocopied without permission from the authors or publisher, provided that publication credit is given and that copies are distributed free. Any commercial reproduction requires prior written permission from the Population Council.

All photos are the property of the M athare Youth Sports Association's Shootback project. 


\section{Foreword}

Adolescence is a time of transition from childhood to adulthood when gender disparities in opportunity and expectations become pronounced. Boys begin to enjoy more privileges; they gain autonomy, mobility, and have more social opportunities-including participation in sports- than girls. For girls, restrictive gender norms weigh heavily on their ability to actively participate in community life. M oreover, the behavior of boys in the public space inhibits girls from participation in sports and denies them the positive social and health benefits that boys have long enjoyed.

There are few examples of largescale programming efforts in the developing world that explicitly link girls and sports. This case study documents for the first time the process of integrating girls into a community-based youth sports program. It tells the story about the power that is unleashed when girls are given the opportunity to play. The authors describe how the M athare Youth Sports Association (M YSA), begun in 1987 as a self-help club for boys that linked sports and environmental improvement, has evolved into a successful program that provides new opportunities for boys and girls alike in the poorest neighborhoods of $\mathrm{N}$ airobi.

O ver the years M YSA has grown into a large, self-sustaining development organization that operates-in addition to an extensive football program-an HIV/AIDS education program, a photography project, an educational scholarship program, and numerous other community service and environmental education projects. Incorporating girls into its programs has helped to validate M YSA as an association for all young people- not just boys.

In many countries in sub-Saharan Africa, establishing youth centers is a popular program approach for reaching young people. This model involves either stand-alone reproductive health clinics that target young people or multipurpose centers that offer recreational and vocational services, reproductive health information and clinical services, and life skills training. A significant expense of such programs is the cost of the youth center itself and the network of peer educators and staff that perform outreach services.

A recent evaluation of one such youth center program-established at the same time as M YSA and targeting the same population of adolescents in $\mathrm{Nairobi-revealed} \mathrm{gross} \mathrm{under-}$ utilization of services by teenagers, and virtually no participation by girls. M oreover, a survey of the young people and their parents in the center's catchment area showed that while the youth center cost twice as much to operate annually as MYSA's sports program, three times more teenagers were aware of MYSA's programs than were aware of those at the youth center. The evaluation also highlighted a key advantage of the MYSA approach: Because sports activities take place in open fields near where young people live, parents are more likely to let their girls participate than they are to let them attend a youth center. Furthermore, because the M YSA program evolved naturally out of community-defined needs and the active engagement of youth, the overall acceptance of the program is far greater.

"Letting Girls Play" is important reading for those developing programs for young people- particularly young women.

While MYSA has a long way to go in achieving gender equity, it has learned firsthand how sports can be a vehicle for social development and for the transformation of gender norms. M YSA has demonstrated that sports can help boys and girls develop new skills, consolidate friendships, and break down social and gender barriers to personal achievement.

Ayo Ajayi

Regional Director, East and Southern Africa

Population Council 


\section{Acknowledgments}

We would like to extend our appreciation first to Judith Bruce for her intellectual guidance and foremost to the young women and men of and to D ebbie Rogow for her adviceand encourthe $M$ athare Youth Sports Association for their agement throughout the writing process. Erica time, energy, and insights. We thank also Chong, Elizabeth M cGrory, and Carole O glesby Ayorinde Ajayi and Annabel Erulkar for their provided useful comments on early drafts. Finally, ongoing support of this project and our Kenyan research team, including Lucy N ganga, Millicent M uthoni, Mathew N ganga, Japeth O ndieki, and Lydia 0 wuor. Special thanks go this case study would not have been possible without the financial contributions of the $G$ ates and Turner Foundations, the Cabot Family CharitableTrust, and the Population Council. 


\section{Introduction}

Adolescence is a powerfully formative transitional phase between childhood and adulthood when attitudes are consolidated, skills are acquired, health behaviors are formed, and life courses are charted. It is a period marked by creativity, energy, and resilience, which, if properly tapped, can lay the foundation for a healthy future. Yet in many settings, adolescence is a time in which the world expands for boys and contracts for girls, and gender disparities in opportunity and expectations become pronounced. $M$ any adolescent girls have narrowed social networks and few collective spaces in which they can gather to meet with peers, receive mentoring support, and acquire skills. Girls' lives become increasingly restricted to the domestic sphere- nominally in order to protect them from dangers outside the home.

This disparity in girls' social access to their peers and to public space begins in childhood and is exacerbated in adolescence. Very often girls' physical mobility is curtailed by cultural norms and conditions that determine where it is safe and/or acceptable for them to go. W hile parents are concerned about the well-being of all of their children, they tend to control their daughters' movements more tightly than those of their sons - and in some instances for good reason. Fearing the watchful gaze of males, the temptation of unapproved or unsanctioned activities, or more generalized violence in the community, parents want to protect their daughters by restricting their mobility. This in turn, narrows girls' options for full participation in public life. ${ }^{1}$

\section{Safe and Supportive Environments}

Adolescent girls and boys need safe and supportive environments. This is a concept that has received considerable international attention and has been articulated by the World $\mathrm{H}$ ealth O rganization (WH O 1999) as follows:

A safe and supportive environment is part of what motivates young people to make healthy choices. "Safe" in thiscontext refers to absence of trauma, excessive stress, violence (or fear of violence), or abuse. "Supportive" means an environment that provides a positive, close relationship with family, other adults (including teachers, and youth and religious leaders), and peers.

For girls especially, the idea of a safe and supportive environment is critical, given the burdens and limitations placed on them by parents and social institutions that intensify as girls approach adolescence. Safe and supportive environments can provide girls with a place in which they are treated with dignity and through which they can:

- D evelop new and valued skills;

- Form friendships, receive and give peer support, and enhance their social networks;

- Enjoy freedom of expression and move ment;

- Receive mentoring support from trusted adults, who can serve as girls' advocates; and

- Take advantage of new learning and educational opportunities.

Access to Public Space

A separate yet related issue has to do with girls' social visibility and access to public space. While in many countries "public space" is not legally defined, there are designated places where citizens can go for recreation, education, entertainment, and to participate in political

${ }^{1}$ This unofficial restriction on female mobility tends to persist throughout life. While not necessarily codified, there is a functional curfew for women in many parts of the world- be it an urban park in a Western city or an impoverished community in the developing world. 


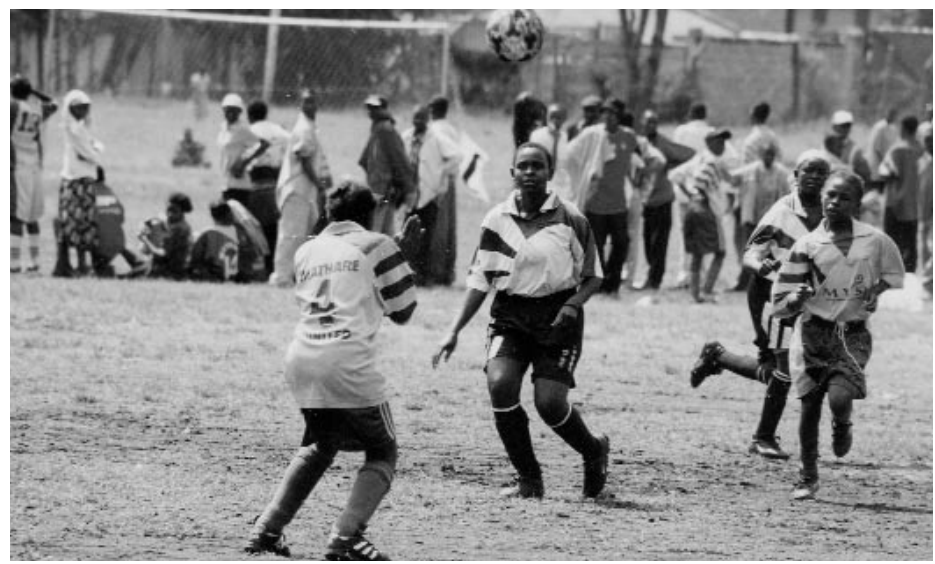

Spectators watch as girl's teams play on an open football field in public space.

life. Typically, the kinds of public spaces that are seen as legitimate venues for females- markets, health clinics, and so forth-are those that enable women to fulfill their domestic roles as homemakers and mothers. In contrast, public spaces for males are less narrowly defined and not necessarily linked to their gender roles.

W hether or not public spaces are formally recognized as such, safe access to them breaks down along gender lines. Females have a much more difficult time- and, in some cases, are completely excluded from-visiting spaces such as town halls, parks, and sports stadiums unless they are accompanied by men. While these public spaces may have been intended for general public use, all too often girls and women are too intimidated to use them for fear of physical or psychological retaliation by men and/or authorities. In this way, "public space" de facto becomes men's space.

Sports as a M echanism for Giving Girls

Space of Their $O$ wn and for

Bringing Them into Public Space

We posit that participation in non-elite sports programs appropriate for girls of average physical ability and skills can meet the simultaneous needs of offering girls new venues in which to gather and breaking down restrictive gender norms. To date, there have been few examples and virtually no documentation of girls' sports programs in developing-country settings. Yet as significant numbers of girls begin to participate in sports and as female athletes gain public recognition, girls acquire new community affiliations, mentors, access to new venues, and begin to more openly participate in community life. Girls' participation can begin to change community norms about their roles and capacities. In this way, sports may be a catalyst for the transformation of social norms.

Throughout Africa and, indeed, much of the developing world, sports have been viewed as an exclusively male domain; in fact most "youth" sports programs have in reality been for boys alone. H owever, as sports have begun to include girls and women worldwide, policymakers and program leaders are beginning to sense the potential of participation in sports to enhance girls' lives.

\section{Case Study}

This case study documents a remarkable effort in Kenya that has helped to create spaces for girls that draw them into sports and community service. It describes the experience of the $M$ athare Youth Sports Association (M YSA), a nongovernmental organization (NGO) based in an impoverished urban setting, and its efforts to integrate girls into a communitybased, large-scale youth program. This dynamic grassroots organization, which seeks to link youth development, sports, and environmental activism, provides a fascinating example of the role of sports in development, as well as its potential to transform gender norms.

W hile we address broad conceptual and programmatic concerns, this case study is first and foremost about girls and their experiences playing football as members of the $M$ athare Youth Sports Association. We document the nature of girls participation in sports and in 
the organization itself, paying particular attention to impediments to their full participation. Assessments of the kinds of social and institutional supports needed to bolster the success of these efforts are also discussed. We review the steps taken by M YSA to transform the ways in which girls think about themselves and the ways in which their communities perceive them. Finally, we offer a set of guiding principles for program planners who are interested in developing programs for adolescent girls in settings similar to that of $M$ athare.

\section{Benefits of Sports for Girls: An Emerging International Perspective}

Favorable $\mathrm{N}$ ational and

International Frameworks

In recent years, sports and physical education have begun to appear on the development agendas of many countries and international bodies. At the Fourth World Conference on Women held in Beijing in 1995, the Platform for Action made specific reference to sports and physical activity for girls and women (paragraphs 83[m], 107[f], 280[d]).

Numerous national and international documents acknowledge the rights of girls and women to full participation in all aspects of public life, including sports and physical education. The United Nations Educational, Scientific, and Cultural Organization's International Charter of Physical Education and Sport (adopted in 1978) states:

One of the essential conditions for the effective exercise of human rights is that everyone should be free to develop and preserve his or her physical, intellectual, and moral powers, and that access to physical education and sport should consequently be assured and guaranteed for all human beings.

Article 12 of the African Charter on the Rights and Welfare of the Child (1990) states:

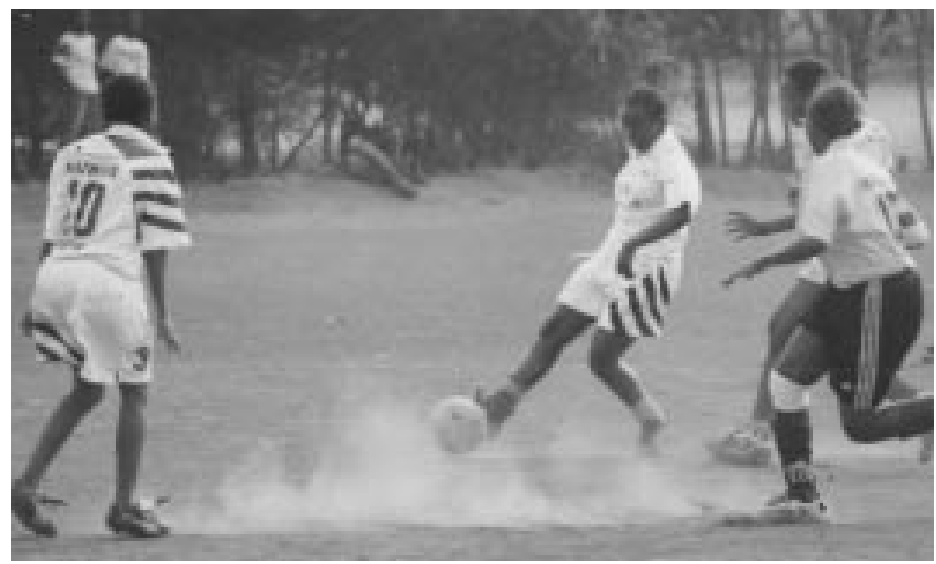

Access to land is an ongoing challenge; here the dusty, red-clay terrain provides a basic playing field.

States Parties recognize the right of the child to rest and leisure, to engage in play and recreational activities appropriate to the age of the child and to participate freely in cultural life and the arts.

In most countries, ministries of youth and sports, national sports federations, and Olympic committees provide a context and structure for sports programming. Among African countries, leaders have long assumed that sports have the potential to advance national pride and help countries gain international recognition. W hile most ministries have policies that acknowledge the equal rights of boys and girls, in practice relatively few of these policies have been put into operation. In recent years youth sports programs have begun to flourish, yet the extent to which this burgeoning interest in sports has touched the lives of girls remains unclear. It is time to capitalize on the favorable, albeit unimplemented, policy environment surrounding girls' and women's sports.

\section{What the Research Tells Us}

Considerable research has documented the links between girls' sports participation and positive health and social outcomes in Western settings. In the U nited States, for example, the 
President's Council on Physical Fitness and Sports issued a seminal report with the following conclusions: Regular physical activity can reduce girls' risk of developing many of the chronic diseases of adulthood; female athletes tend to do better academically and have lower school drop-out rates than their non-athletic counterparts; and regular physical activity can enhance girls' mental health, reducing the symptoms of stress and depression (President's Council on Physical Fitness and Sports 1997).

The hypothesized links between sports participation and reduced risk of pregnancy were tested in a 1998 study in the United States using a nationally representative sample. Findings indicated that adolescent females who participate in sports tend to become sexually active later in life, have fewer sexual partners, and, when sexually active, make greater use of contraception than their non-athletic counterparts. The findings suggest that sports participation functions as a developmental resource for many adolescent females in ways that positively influence sexual behavior. Interestingly, the study also revealed that sports participation influences the sexual behavior of girls and boys in different ways. For girls, it represents a historical departure from traditional femininity and challenges male privilege and cultural myths about female frailty. In contrast, boys' experiences are an extension of gender expectations surrounding manhood and sexuality, and have amplified traditional gender expectations for males rather than challenge them (Sabo et al. 1998). To date, no such studies have been carried out in the developing world.

The Potential for Girls in D eveloping Countries

The existence of international legal and policy frameworks that support women's participation in sports, national laws requiring equal access and opportunities for females, and an emerging body of evidence establishing the contribution of sports participation to mental and physical health have laid the groundwork for experimentation with a variety of girls' sports programs. Girls in developing countries could benefit significantly from restructured social opportunities in addition to the obvious physical and mental health gains. Sports participation requires dedication, discipline, responsibility to self and others, and adherence to a set of rules of conduct and behavior; in short, it provides structure. Participation in sports provides an opportunity to form friendships and intensify peer networks and to engage in more frequent and meaningful contact with peers. Team membership offers girls a chance to learn how to communicate, cooperate, and negotiate on and off the playing field. Belonging to a publicly recognized team offers a valuable sense of affiliation, and it provides girls with "their own space," both physically and emotionally. Sports bring communities together, uniting coaches, parents, community leaders, and team members in the pursuit of a common goal.

In many settings a maturing girl may be encouraged to view her body as a sexual and reproductive asset to men rather than a source of power and strength for herself. Sports participation may help girls develop a sense of ownership of their bodies and may allow them to rewrite the conventional scripts of femininity that encourage them to establish their selfworth mainly in terms of their sexuality. In addition, because the way girls express themselves may be influenced by the social construction of femininity (i.e., most girls learn culturally appropriate "female" styles of movement) girls' sports participation may counteract this repression by allowing girls access to the more physically active adolescence traditionally enjoyed by boys (Thompson 1995). In this way participation in sports builds girls' sense of 


\section{GIRLS' ADOLESCENCE IN KENYA}

While gains are being made for girls in almost all areas, important differences in adolescent boys' and girls' experiences in Kenya remain. These differences begin in the home, where the disparity between boys' and girls' domestic workloads is most striking. For example, outof-school girls work eight times as many hours in unpaid domestic work as out-of-school boys (Government of Kenya, Ministry of Planning and National Development, Central Bureau of Statistics, and Long-Range Planning Unit 1991). In terms of paid employment, however, boys work more hours than girls, and this gap widens with age. Girls' lack of livelihood skills narrows their options for paid employment.

The disparities between girls and boys are further compounded in school, where, although significant strides have been made in girls' educational attainment, a gender gap exists that widens with age. At younger ages (10-14 years), relatively little difference is found between girls' and boys' school enrollment; however, at ages 15-19, fewer girls are enrolled in school (National Council for Population and Development [ NCPD], Central Bureau of Statistics [CBS] of the Office of the Vice President, Kenya Ministry of Planning and National Development, and Macro International 1999). Moreover, the school environment is often not particularly supportive of girls. In one study, a girl remarked, "Boys come and hold our breasts in class even when the teacher is there" (Mensch and Lloyd 1998).

Studies also reveal preferential treatment of boys by teachers. Girls are often made to feel socially inferior in the classroom and are sometimes referred to as "stupid" or "lazy" by their teachers. Further, girls are more likely than boys to perform menial chores in school such as preparing and serving food or cleaning the classroom, while boys enjoy more leisure time.

With respect to marriage and sexual activity, girls are under pressure to be sexually active whether or not they are married. Because of their economic vulnerability, many young women exchange sex for money. And although the age at marriage for girls has increased steadily through the years, approximately 46 percent of girls in Kenya are married by age 20 (NCPD, CBS of the Office of the Vice President, Kenya Ministry of Planning and National Development, and Macro International 1999). Finally, while adolescent fertility in Kenya has declined overall, the proportion of births to young women in their teens that occur prior to marriage is increasing.

Perhaps one of the most critical issues facing young people is HIV/AIDS. Boys and girls between the ages of 15 and 24 have the highest rate of new HIV infections in the country, and girls in this age group are more than twice as likely to become infected as boys (Government of Kenya, Ministry of Planning and National Development, Central Bureau of Statistics, and Long-Range Planning Unit 1991). Recent surveillance data paint a picture of a rapid increase in HIV prevalence rates among girls ages 15-24. In some districts, rates range as high as 23-38 percent. While these figures are alarming in and of themselves, they are especially striking in comparison to rates for boys of the same age, which are less than half those for girls (US Bureau of the Census 2000). 


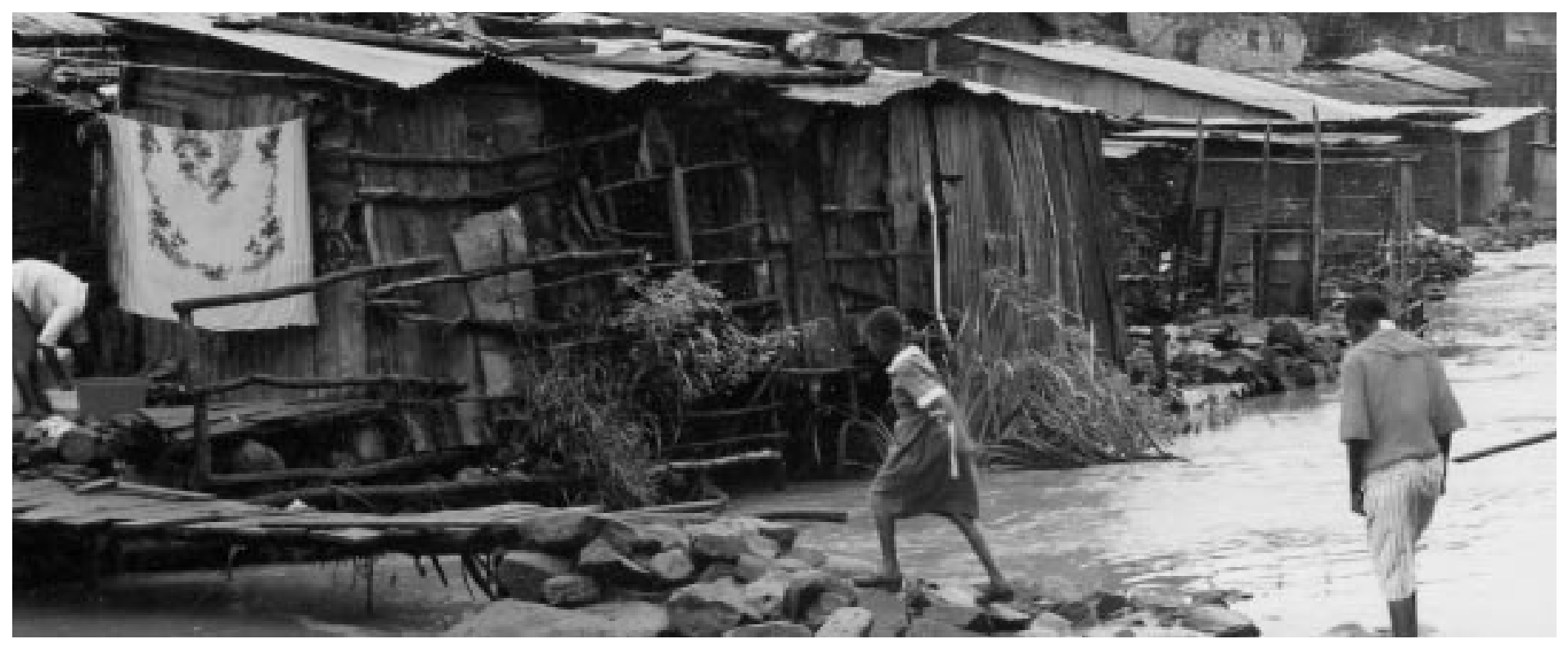

D uring the rainy season, the overflowing $M$ athare River makes getting around difficult for residents.

agency and entitlement. Finally, because many adolescent girls have difficulty articulating their own needs and interests, sports can provide them with an arena for self-expression.

\section{Life in Low-Income U rban N airobi: Where the Story Begins}

$\mathrm{N}$ airobi's slums - officially referred to as "informal settlements"-are not recognized by the government and house nearly 70 percent of Nairobi city residents (Zulu, Ezeh, and D odoo 2000). The Nairobi City Council owns much of the land, and most residents live in rented dwellings. Because these settlements are "informal," the government is not officially obligated to supply them with water, electricity, or other basic amenities such as health clinics or schools. Residents live without sewage treatment or toilet facilities- leaving them with no access to clean water or appropriate sanitation. $M$ any residents rely on the $M$ athare River and its streams for water, while others buy daily supplies in 20liter containers from water vendors. With no proper sewage disposal, most residents use pit latrines or dump human waste in the river.
O rganized garbage collection is a rarity; it is not uncommon to see mountains of refuse piled up throughout the communities.

The extreme poverty in the settlements has serious implications for the social and health outcomes of women and children. Early initiation of sex and the selling of sex by young girls is sometimes encouraged by families. While adolescent boys go on "begging" or "scavenging" missions, girls provide sexual services to boost family income (Zulu, Ezeh, and D odoo 2000).

$M$ athare - the best-known informal settlement in Kenya - is located a few miles northeast of $\mathrm{Nairobi.} \mathrm{Covering} \mathrm{an} \mathrm{area} \mathrm{of}$ approximately 85 square kilometers, $M$ athare was established in 1963 as a settlement for landless people (H ake 1977). Since that time people from all parts of the country have migrated there in the hope of finding land and work. Unfortunately, both of those commodities are in short supply today, and the living conditions in $\mathrm{M}$ athare are some of the worst in $\mathrm{N}$ airobi. M ost people live in small, poorly ventilated single rooms measuring approximately eight square feet, which are subdivided by makeshift curtains for privacy. Homes are 
made of cardboard, wood, or mud and wattle, with roofs of tin or corrugated iron.

\section{Where 0 ur Story Begins}

The potent smell of burning rubbish, exhaust fumes emanating from overcrowded matatus (public vans/buses), and running sewage tells us we have arrived in $\mathrm{M}$ athare. Walking along the winding footpaths one notices the density of housing structures and the lack of roads. Vehicle access is almost impossible in some areas, particularly during the rainy season. O ne sees young girls carrying even younger siblings, children playing in mounds of garbage that contain shards of broken glass, and kiosks stocked with cigarettes, paraffin, and mosquito coils.

The majority of residents are either unemployed or self-employed in the informal sector. A major income-generating activity for many is selling fruits and vegetables in open-air markets or dry cereals from kiosks, or selling cooked foods door to door. Some women do casual labor in nearby quarries or construction sites or are employed as domestic workers in the homes of the middle-income wage earners in the nearby estates. Others brew and sell changa'a, a local alcoholic beverage. Many women sell sex. It is clear that in such circumstances women's sexual vulnerability is exacerbated by their economic vulnerability.

This setting offers few positive social opportunities for the young people who live there. Physical infrastructure is extremely weak, and safe meeting places for girls or boys are almost nonexistent. Because land is at a premium, there is limited open space for residents to enjoy.

It was in this unlikely setting that the $M$ athare Youth Sports Association was founded in 1987 with the goal of, in the words of one of its mottoes, "giving youth a sporting chance." Today M YSA thrives as a testament to the entrepreneurial and resourceful spirit of the young men and women who live there.

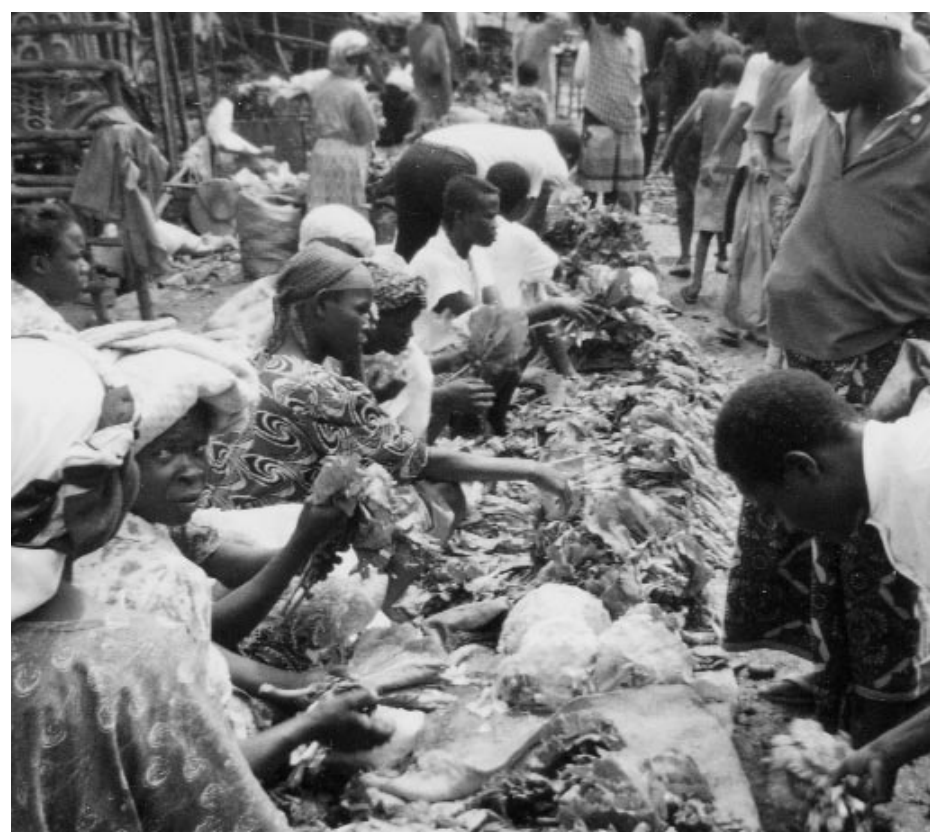

Selling vegetables at the local markets is one of the main incomegenerating opportunities available to women.

\section{M athare Youth Sports Association}

MYSA began as the labor of love of a Canadian expatriate development worker with an interest in youth and environmental issues. As Bob M unro watched boys kicking footballs made of recycled plastic bags and twine around the garbagefilled slums, he began thinking about the ways in which the energy and enthusiasm of these boys might betapped. Munro's initial aim was to organize a small

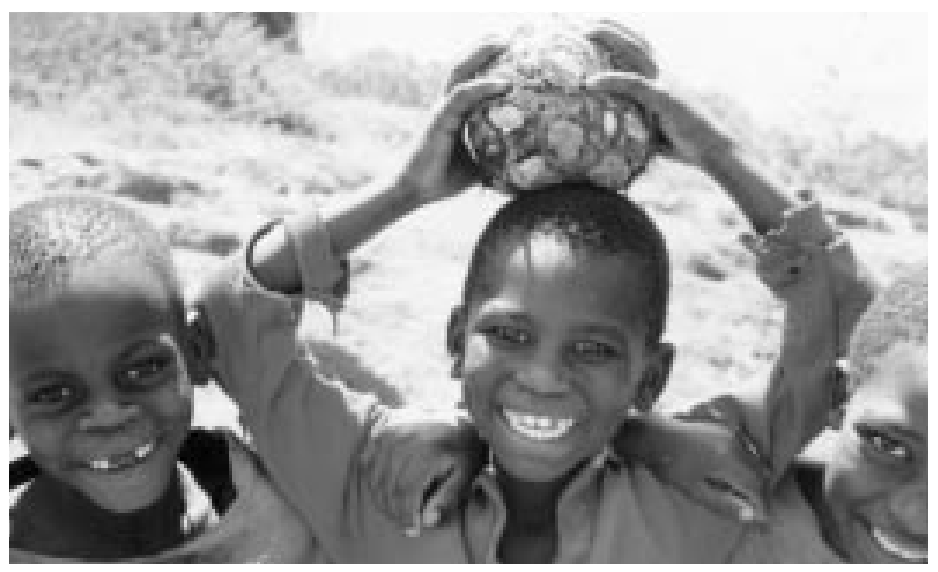

Young people playing with "M ade in M athare" footballs of recycled plastic bags, gum, and twine. 


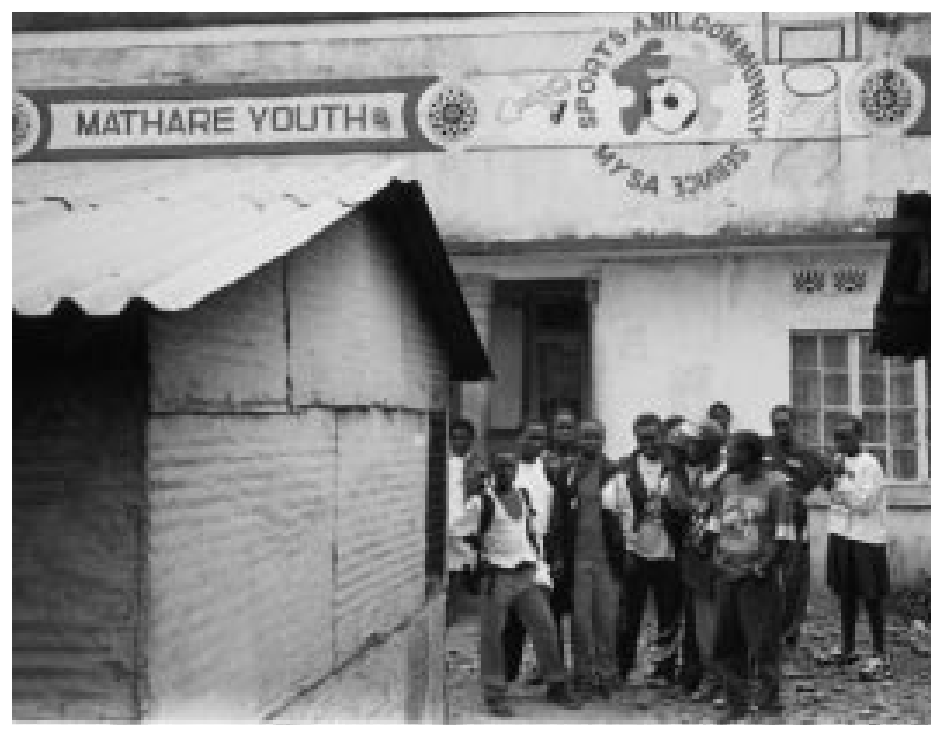

Girls and boys gather in front of M YSA headquarters.

self-help organization that would provide a sports outlet for the young boys of the $M$ athare slums while at the same time improving the environment. From its earliest days, garbage clean-up and environmental awareness were linked to MYSA's football and youth development programs.

In 1988, just one year after its inception, the organization formalized a constitution and registered under the Societies Act of Kenya as an NGO. By 1992 M YSA introduced organized football leagues for girls. That same year, at the Earth Summit in Brazil, M YSA received the U nited $\mathrm{N}$ ations Environment Programme's Global 500 Award for environmental innovation and achievement.

From a dozen or so boys playing impromptu football games in the street, M YSA has grown into an organization that sponsors hundreds of teams and matches, and thousands of male and female players. (For descriptive data and a breakdown of MYSA's membership by gender, see page 13.) Part of M YSA's philosophy is helping its members develop life skills on and off the playing fields. $O$ ver the years M YSA has increased the scope of its programs as well as the numbers of young people it serves, so that today it operates a far-reaching H IV/AIDS education program, an extensive football program, an educational scholarship program, a photography project, and numerous community service and environmental education activities. M YSA continues to discover new ways of working and new program areas to explore.

H ow M YSA Works

MYSA began its work with boys - their boundless energy and passion for sports made developing a community-based sports program for them a logical first step. Boys (unlike girls) were already out in the community, their parents approved of their playing football, and male players were easily recruited. As word of the organization spread, teams formed, leagues grew, and M YSA began to take root in the community. The organization grew rapidly, expanding its coverage to approximately 80 square kilometers throughout the eastern areas of $\mathrm{N}$ airobi city.

The main avenues through which one becomes a member are: (1) becoming a football player, coach, or referee; (2) participating in clean-up campaigns; or (3) serving as a volunteer in one of the community service programs. The vast majority of MYSA members enter through the football program. As with most membership organizations, level of participation varies from individual to individual. M YSA is an important part of the lives of many of its members - some say that M YSA is their family. $M$ embers spend numerous hours per week either at M YSA headquarters or volunteering. It is difficult to quantify the importance of M YSA to its members; time spent is only one indicator.

Since its inception, the benefits of M YSA membership have exceeded athletic training and camaraderie. 0 nce an individual has been a member for at least two years, he or she is eligible for any number of benefits, including educational scholarships, specialized skills 


\section{MYSA PROGRAMS AT A GLANCE}

MYSA operates several programs that have been developed in response to the expressed needs and interests of the community it serves. The programs are organized around five main themes:

Education: MYSA provides financial assistance to selected members and their families through educational scholarships.

Information: HIV/AIDS education activities consist of a far-reaching peer education program, the objective of which is to create awareness of HIV/AIDS and other social and health problems. The Shootback photography project provides training to MYSA members in basic photojournalism with the goal of documenting life in the Mathare slums. A relatively new project is MYSA's Web site (www.mysakenya.org).

Outreach: The main focus of MYSA's Family Support project is to secure the release of arrested street children and reunite them with their families. The project also seeks to improve the conditions of the juvenile courts and provide care, support, and meals to incarcerated young people. This program of work demonstrates MYSA's commitment to social justice and civic responsibility.
Environment: Known as Slum Clean-up or simply Clean-up, this program has been a hallmark of MYSA since its inception. I seeks to improve sanitation by removing and disposing of garbage properly, while providing young people with access to better public space.

Sports: Sports is MYSA's core program. The majority of MYSA members enter through the sports program, which consists primarily of organized football leagues. Leagues are open to boys and girls 9 - 18 years old who reside in the MYSA catchment area. Recently, a sports academy has been established to provide high-level training to MYSA youth and to develop effective coaches and referees. To generate income, the academy also offers its services to organizations both within and outside the country.

For more information about MYSA and its programs, visit its Web site at www.mysakenya.org. training, participation in international tournaments, employment with M YSA, and practical experience in facilitating groups, organizing meetings, and running projects.

At its most fundamental level MYSA is a community action group that draws in young people and enables them to make viable contributions to public life. Its broad agenda embraces a commitment to education, to the active and meaningful civic participation of its members, and to the creation of a cadre of talented young people with an interest in the larger world. Through its work, M YSA has learned firsthand that there are numerous administrative and programmatic underpinnings to such a mission.

\section{Support and Encouragement for Education}

O ne of M YSA's aims is to encourage and, where possible, help its members to stay in school. In recognition of the financial difficulties many M YSA families face, a scholarship fund has been established to help pay the school fees of some members. Girls and boys have received scholarships in numbers proportional to the total number of girls and boys in the program. In addition, because M YSA employs some of its members, employees' earnings can help pay school fees. 


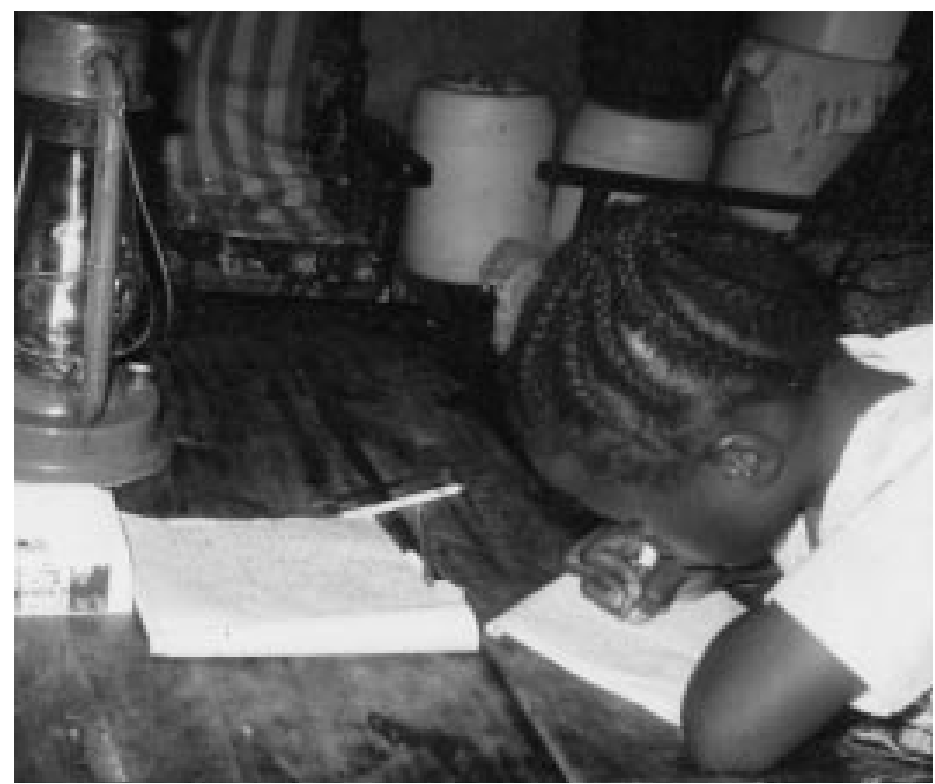

A hardworking student beneficiary of M YSA's educational scholarship program studying by the light of a kerosene lamp.

M YSA's commitment to helping its members stay in school is evidenced by its approach to scheduling activities so that they do not conflict with school; most MYSA activities take place in late afternoon, after school, and most matches and tournaments are played on

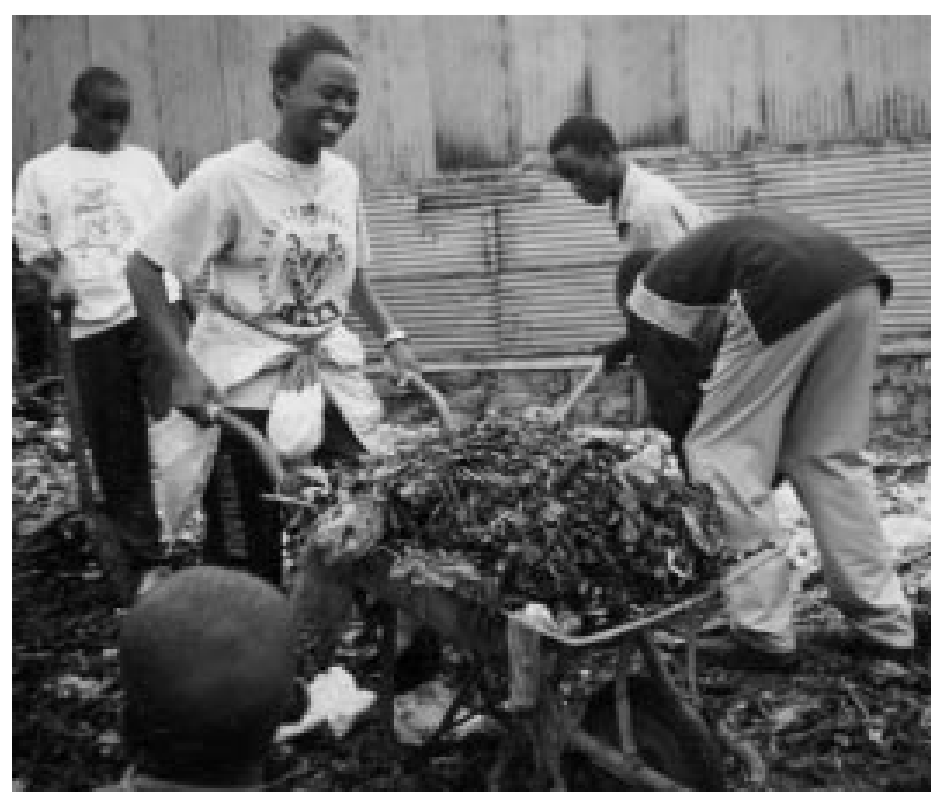

Saturday clean-up: A commitment to environmental activism is shared by M YSA members. weekends. During certain times of the year when training routines are more intense, parents and school authorities are notified and permission is sought to excuse students from their regular schedules.

\section{D eveloping an Active Citizenry}

O ne of M YSA's overarching principles is encouraging the civic participation of its members. The organization believes that its members should be role models in the community, and, as such, it has developed a code of conduct to which members pledge commitment upon joining. In keeping with the organization's philosophy that actions speak louder than words, members are required to participate in some form of community service. MYSA's best-known community service activity is garbage clean-up. Initially, the impact of these efforts was cleaner surroundings and better football fields to play on. Later the activity translated into worldwide recognition of M YSA's contribution to linking youth and environmental awareness, as evidenced by its U nited Nations Environment Programme award for environmental innovation.

M YSA members gain a positive visible presence in their community in other ways. For example, members garner public recognition and respect by wearing the M YSA uniform, a brightly colored green and yellow jersey emblazoned with MYSA's logo. Wearing the jersey is a source of both pride and protection for members. M YSA youth are considered by most community residents to be "good kids." Even the police view them positively, a radical departure from the general perception of the urban poor as both perpetrators and victims of crime.

M YSA supports its members by providing assistance in obtaining visas and passports for those selected to play in the N orway Youth Cup. H owever, in order to obtain a visa or passport, a member must have a birth certificate or identi- 
fication card. ${ }^{2}$ Given that nearly half of M YSA's members are born at home, few, if any, have this important documentation. Participation in the tournament, therefore, may provide the impetus for parents to obtain birth certificates for their children, so that they can then apply for passports and visas. Such assistance is invaluable for boys and girls alike, but perhaps more so for girls, who might otherwise never have the opportunity to gain an identity independent of their status as daughters or wives.

\section{Life Beyond $M$ athare}

M YSA believes its members are "citizens of the world." As such, it publicizes its work, invites international guests to visit, and, where possible, arranges for cultural exchange and international travel for selected members. Each year since 1990, MYSA teams have qualified for participation in the Norway Youth Cup, the world's largest youth football tournament. Playing in the N orway Youth Cup looms large in the aspirations of many and is seen as a major benefit of M YSA membership.

Recently MYSA has begun providing technical assistance to other organizations developing similar programs. M SYA staff and its members have visited programs within Kenya and other countries in the region. $M$ embers have participated in a variety of international youth congresses. M ost recently, keeping in step with the information age, M YSA has created a Web site to meet and greet its "virtual visitors."

\section{T he Girls Program}

Five years after the creation of the boys' teams M YSA began to consider expanding program activities to include girls. During a trip to N orway in 1992, M YSA boys saw, for the first time, female athletes playing football, and the seeds for the creation of a girls' program were sown. Seeing strong, talented female players was an eye-opening experiencefor many M YSA boys.

U pon their return to $M$ athare, some of these boys and MYSA senior management were eager to start girls' football leagues. They were convinced that Kenyan girls could learn to play as well as Norwegian girls, and they knew that the girls of $M$ athare would benefit just as they had. The timing was right: D onors were beginning to provide increasing levels of support, an HIV/AIDS awareness program had been launched, and new initiatives were flourishing. A combination of good intentions and dedication provided the engine that propelled the M YSA girls' program into existence.

\section{Evolution of the Girls Program}

Setting up a girls football program was not simply a matter of gathering a group of girls

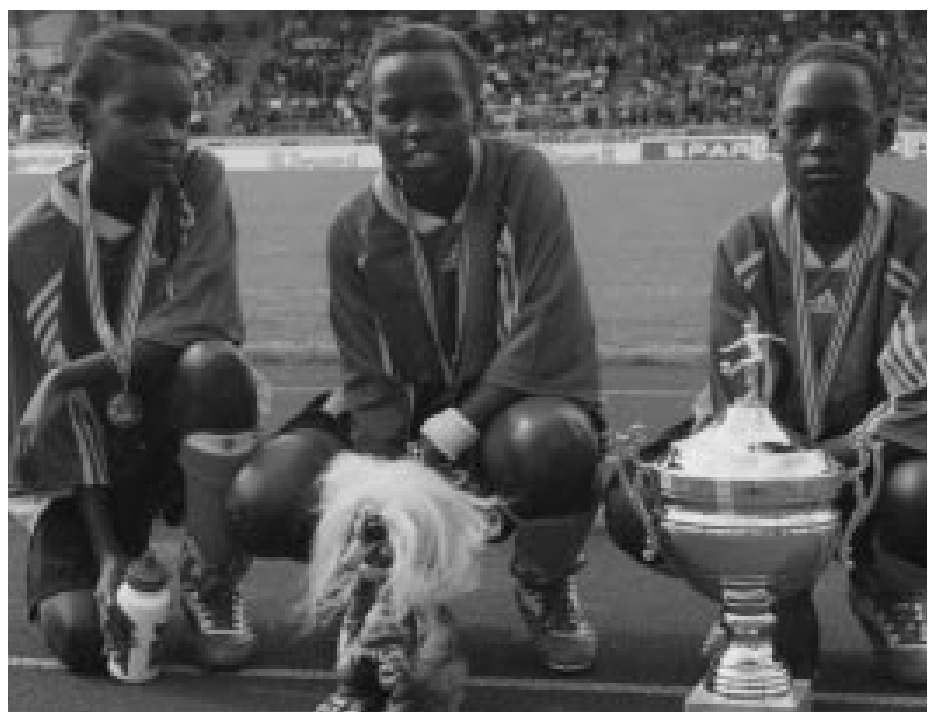

Recognized for their achievements, M YSA girls capture the trophy.

\footnotetext{
${ }^{2}$ Birth certificates are required in order to obtain a national identification card, which is needed for voting, opening and operating a bank account, obtaining a driver's license, military conscription, and employment.
} 


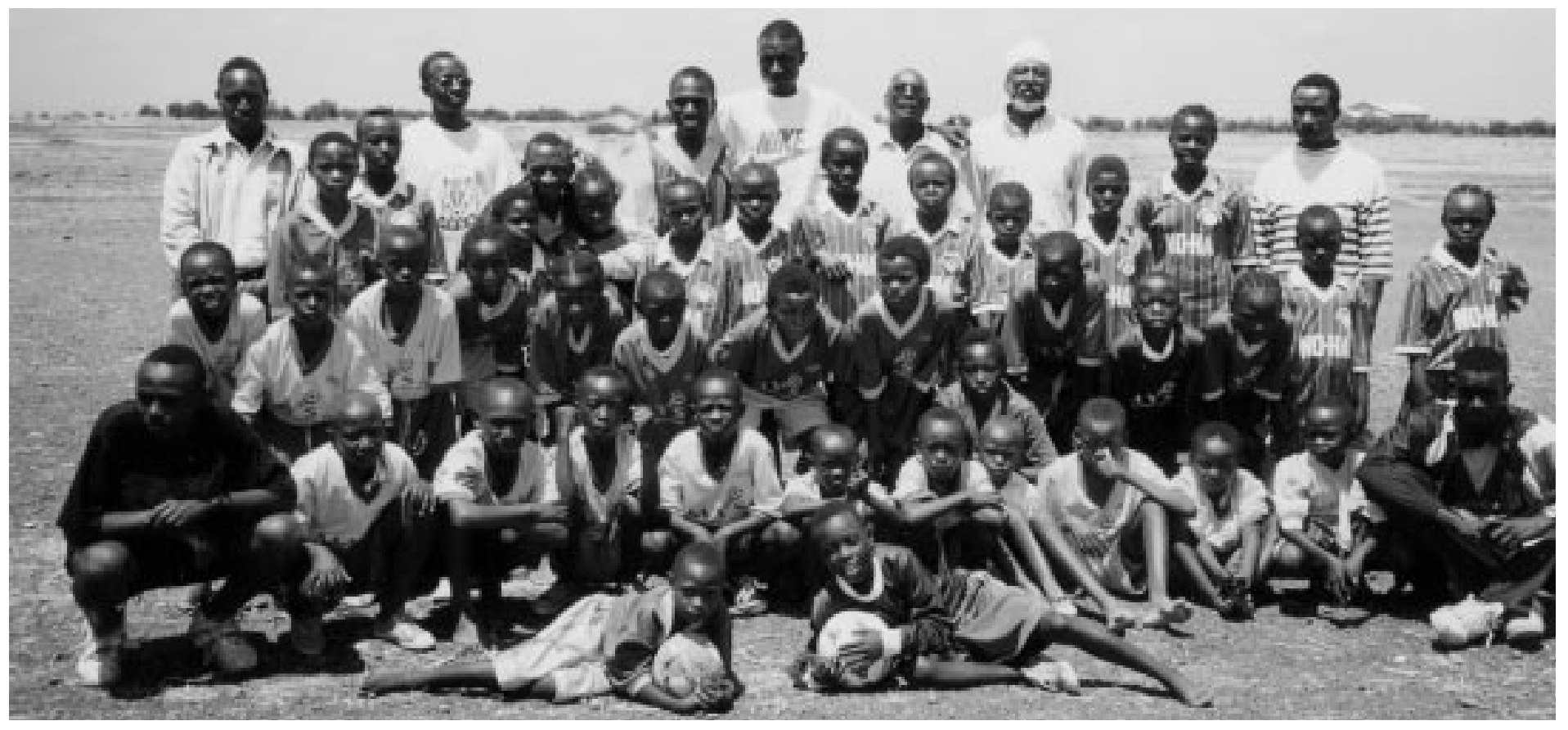

O ne of M YSA's many boys teams. B oys outnumber girls on teams in each age group.

together and forming teams. It required considerable thought and effort and an understanding of the physical and social constraints on girls' lives. Parental and community support had to be garnered and accommodations in girls' schedules and in the program made in order for girls to participate. At it turned out, prevailing gender roles weighed heavily on the process of integrating girls into MYSA.

MYSA's beginnings as a relatively small, provincial, all-male organization did not prepare it for the complexities presented by integrating girls into its programs. Given the prevalence of traditional attitudes and beliefs about gender roles within Kenya, the challenges in setting up a girls' program would prove to be considerable. Looking back, staff readily admit that they didn't fully compre hend what would be required and had underestimated the enormity of the task: M YSA was not simply setting up a girls' football league; rather, it was embarking on a process of transforming gender norms.

The first girls' team began with fewer than a half dozen girls; some had brothers who played, others had learned about football by watching the boys' teams, and some simply wanted something new and fun to do. These original members were instructed to find other girls to play; in short, they were asked to generate interest among their peers. They began by recruiting sisters and friends. The earliest girls' teams - with names like M ighty Kickers, Bafana Bafana, and Español Girls- were formed at a time when the boys program was flourishing and MYSA was becoming an increasingly important presence in the community.

$O$ ver time more girls came forward, yet parental concern remained a significant impediment to their participation. It became increasingly clear that parental approval of girls' participation would require dedicated efforts on the part of MYSA staff. In some instances staff visited parents at home, where they would describe the program as an opportunity for girls to learn and develop new skills and do what boys were able to do- a first step in building girls' capabilities.

Parents were asked to come watch a football match or to help with the scoring, with 
the idea that engaging parents was one way to allay their fears. The girls' program grew slowly. Girls recruited other girls, and more and more girls' teams were formed. By 1996 M YSA staff began organizing matches and leagues for girls and providing basic equipment and coaching. Initially, all the girls' teams were coached by boys. Today some girls are coaching teams, but male coaches continue to outnumber female coaches.

The continued success of the girls' leagues has meant that girls from $M$ athare now dominate women's football in Kenya. In 1996 a major turning point for the M YSA girls' program occurred: The first girls' team was invited to play in the N orway Youth Cup. Since that time, the girls' teams have been extremely successful, winning silver and bronze prizes most years. O ne year, the girls' team was awarded a garbage collection truck for use in clean-up activities.

\section{YSA M embership by Age and Gender}

Engaging and retaining adolescent girls in sports programs is a challenge everywhere, and perhaps even more so in settings where doing so tests social norms. At M YSA, boys outnumber girls in all age groups in each year for which data exist. Beginning in 1997, the first year in which reliable data exist, boys outnumber girls by approximately four to one, and for some years and some age groups by as much as five to one. Age groups are defined by the higher age of a two-year range. For example, the under-12 group (U12) is for girls ages 11-12. Girls older than 12 years are not eligible to play in the U12 age category, but younger girls may. Players generally can play up an age category but never down. This age categorization system holds for all age groups and is fairly standard for most sports.

It is interesting to note that the largest numbers of girls and boys are found in the youngest age group-U12-in each year. This finding corroborates a universally accepted principle regarding girls' participation, that is, it is easier to recruit and engage younger girls. Younger prepubescent girls are more often allowed to play and "act like tomboys" than older girls. In some sense their roles are more androgynous - and they are able to move freely within male and female roles (Thompson 1995). At puberty, and particularly at the onset of menses, many girls are discouraged and, in some instances, forbidden to continue their participation in sports.

It is noteworthy that in all years there are few teams for girls ages 17-18. Aside from the original group who started the girls' teams in 1996-97, there are virtually no new girls'

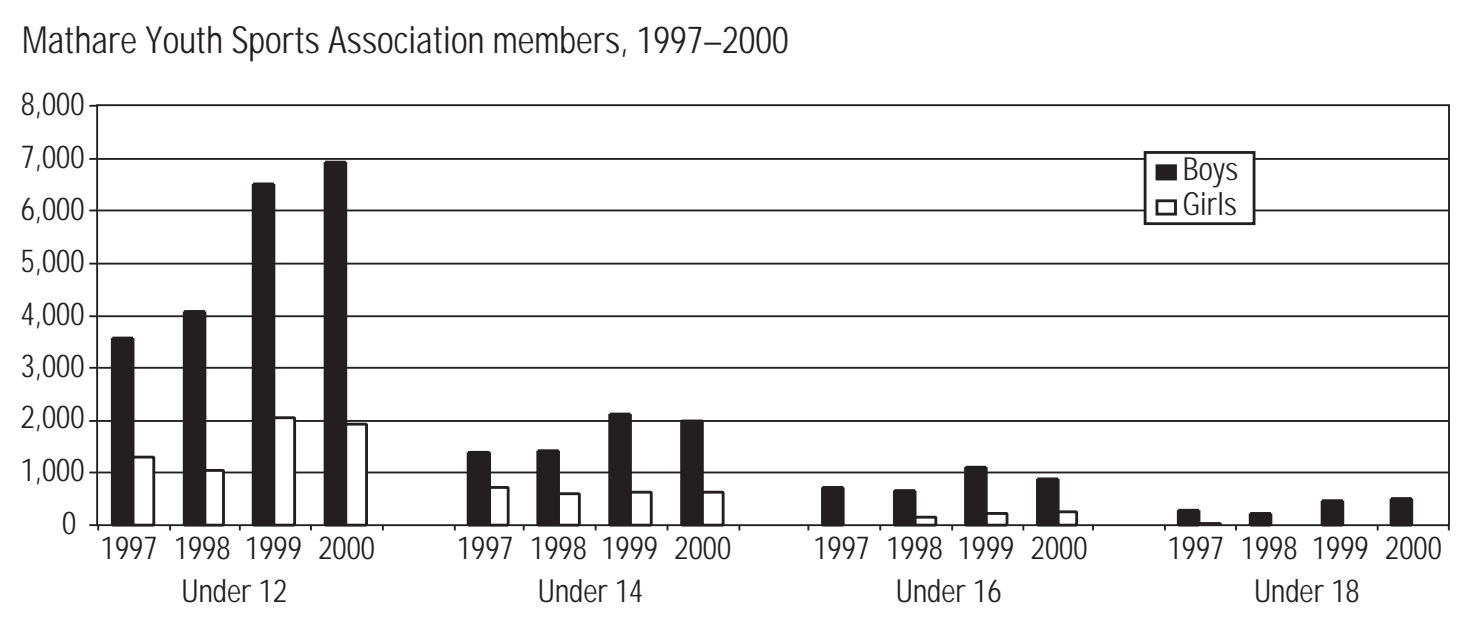


teams in subsequent years for that age group. The lack of program opportunities and support as girls age likely reflects several social conventions. For example, by the time many girls reach the age of 17 or 18 , they have already begun taking on adult roles and responsibilities as expected in their communities. For others, interest in sports may wane as social, economic, and marital pressures become more pronounced. A deeper understanding of the antecedents to this trend could inform future programming.

In 2001, given the small number of girls participating in the older age groups, M YSA decided to collapse the two oldest age categories- U 16 and U 18-into one group for all girls above 16 years of age. The above-16 (A16) group allows girls 16 years and older the opportunity to play if they wish.

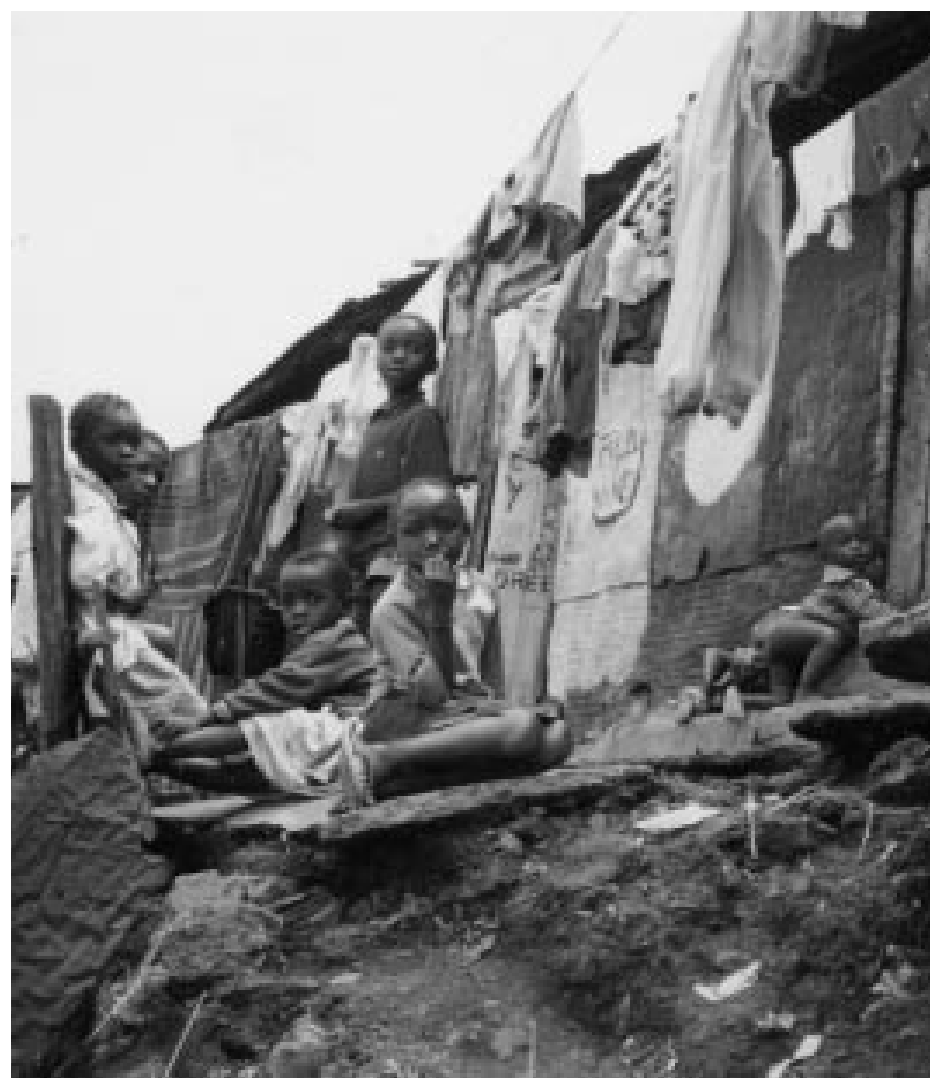

Girls often shoulder the responsibility of caring for younger siblings.

\section{The M YSA Girls Program from Multiple Perspectives}

Building and sustaining programs for girls requires the input and support of several constituencies. Parents, boys, and community leaders often exert considerable influence over girls' movements, safety, and ability to participate in programs. It is thus vital to understand the perspectives of these groups. This is particularly the case for parents, who often serve as girls' main gatekeepers. The observations that follow come from focus-group discussions and in-depth interviews with girls, boys, parents, and M YSA staff members.

\section{W hat Parents T hink of the Program}

From the inception of the girls' program it was clear that parents' opinions of M YSA and the appropriateness of girls' playing football would be key determinants of girls' participation. Initially, many parents were skeptical about the utility of their daughters' participation. Some felt that it would take daughters away from chores and childcare responsibilities, or, quite simply, that "sports are for boys."

O ne 15-year-old girl describes how her father's opinion, while initially negative, changed over time:

When I started playing for MYSA my father would say that thereisno football for girls, and he would beat me up. So whenever I wanted to go and play, my mother would cover up for me by saying that she had sent mesomewhere. Then when I went to $\mathrm{N}$ orway, he started liking it.

$M$ any parents felt strongly that participation in M YSA should not interfere with girls' numerous household responsibilities. For example, girls are often charged with the care of younger siblings and food preparation, which leaves very little time for sports or other leisure pursuits. It was clear that if girls wanted 
to play, they would need to balance their domestic responsibilities with time for sports. In short, they would need to become experts at time management. In some instances, mothers and daughters worked together to find solutions. As the mother of one girl said:

This time I had a child who had just turned one year old, and I used to do hairdressing near my house. So we used to organize ourselves. If she [daughter] knew she had a match to play she would finish her chores early before going for the match. Even if it meant waking up early. Especially when I was pregnant. She was so helpful.

Another key concern of parents was girls' mobility - where they go, when, with whom, and how. Parents insisted that their daughters be home before dark and that they come straight home- no idling or stopping at friends' homes to chat. 0 ne mother's description of waiting for her daughter to return home one evening illustrates her desire for her daughter to have new opportunities yet to be safe:

Diana had not arrived home and it was getting to dusk. The reason was because of a traffic jam. She made us laugh because she had worn shorts that day, which made her look like a boy. She decided to drop off [the matatu] and walk home [Along the way] there is a bridge she did not want to cross alone, so she decided to accompany an old man. This old man thought she was a boy and addressed her as a boy. The old man asked her, "W here are you [coming] from, young boy?" "From playing football," she answered.

$M$ y daughter is very clever.

While expressing concern for her daughter's whereabouts, this mother was heartened by her daughter's resourcefulness and ability to navigate her environment.

Parents, particularly mothers, were aware of potential threats to their daughters and

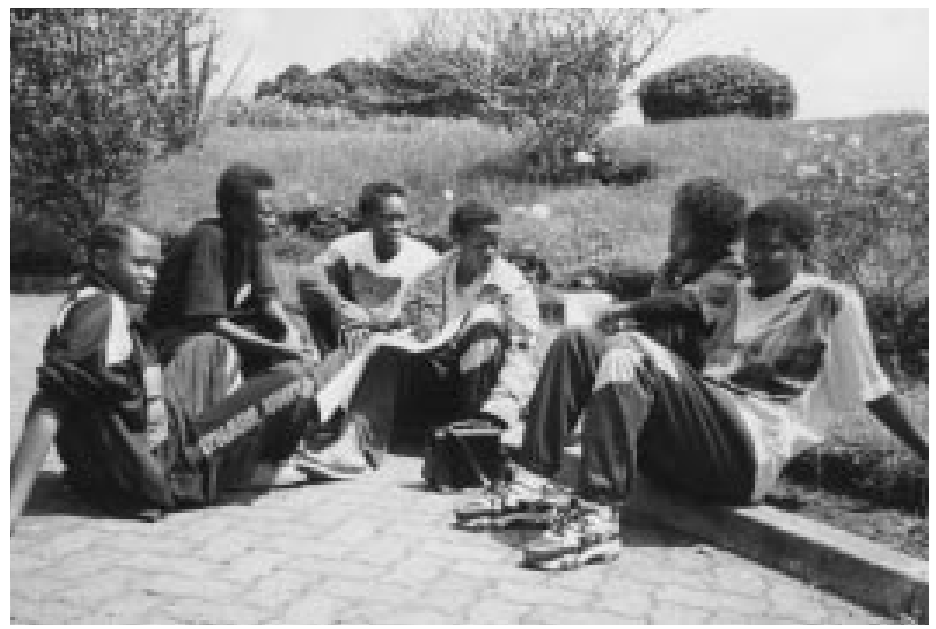

Girlś leaders meet to discuss program activities

understood that they must be careful not to be victimized. Parents realized that while boys face safety issues of their own, they are able to move more freely within the community and with less fear. Parents also realized that an unsafe environment had arguably graver consequences for females than males.

M YSA had not anticipated how important the issue of girls' safety would be for the girls' program. Initially, the organization left it up to the girls to devise strategies for ensuring their own safety. Girls were also charged with managing parents' concerns about safety; no efforts were made to address this issue systematically. Eventually, creative programmatic interventions have helped overcome this challenge.

D espite their initial skepticism, many parents are now favorably disposed toward M YSA, stating that M YSA has been beneficial to their daughters and to the community in general. For example, M YSA has helped families pay school fees through the scholarship program. 0 ne proud mother remarked on her daughter's accomplishments: "She has worked hard and won a scholarship."

One 14-year-old female football player spoke of her father's support from the beginning: 
$\mathrm{He}$ is also happy with my decision to take up football. He feels proud of me when his friends tell him what a good player I am.

O verall, mothers have reacted positively to their daughters' involvement in sports. They have expressed pride, particularly when their daughters have gotten the opportunity to travel. As long as participation in M YSA is viewed as beneficial, most mothers say they have tried not to create obstacles that would prevent their daughters from playing. In the words of one mother:

I saw there was no need to stop her, since she thought it was good for her and it was a new thing, this sports. W ho knows maybe this sport may help her in future.

What I like is the way they take these young children and not only train them in football but they arealso taught about many things. For example, Lydia told me that there are usually programs where they are taught about AIDS, how they can take care of themselves as young girls. [They also] participate in clean-

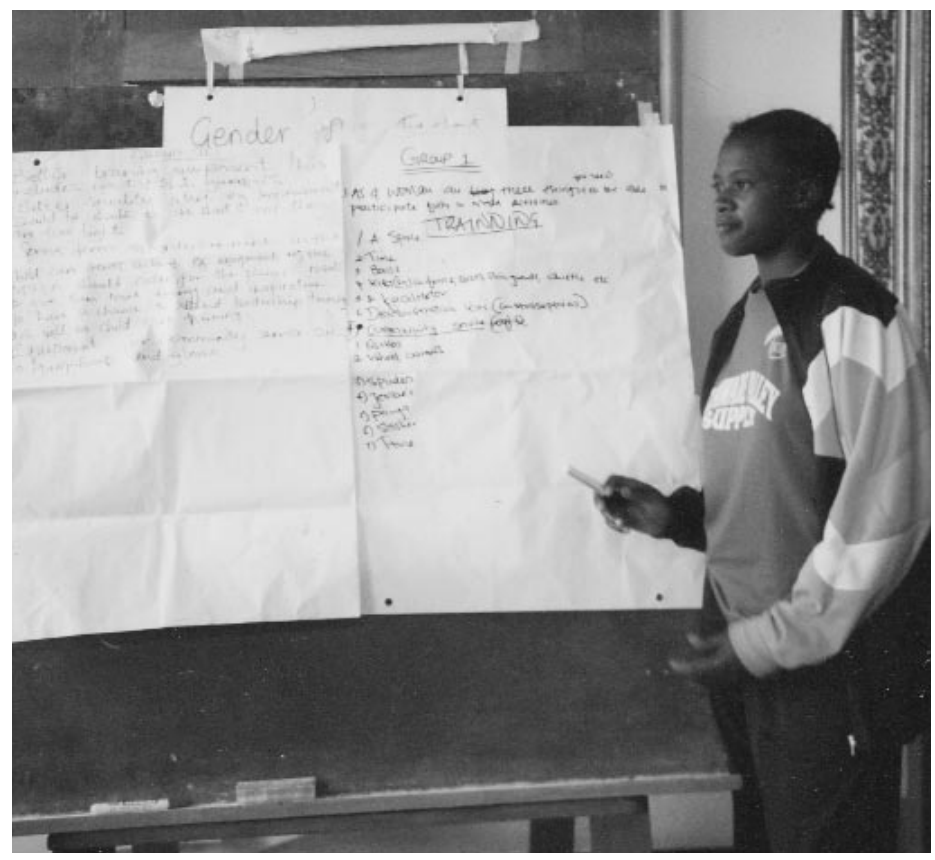

A female leader participating in a training workshop. up activities and picking up rubbish. They [M YSA members in general] are also respectful.

Another mother remarked:

Sports is good, you learn how to play and score. Your team cheers the scorer and asa parent you feel good about your child.

\section{Girls Perspectives on the M YSA Experience}

$M$ any of the ben efits girls accrue from participating in MYSA are those that boys were already enjoying: developing new skills, consolidating friendships, traveling, belonging to a well-known and respected organization, and participating in community life. W hile these are valuable for both boys and girls, the positive benefits for girls- who tend to be at a disadvantage relative to boys- are perhaps even more profound.

Team solidarity: Building friendships, having fun, and gaining confidence. Almost all girls mentioned that being with friends, having fun, learning new information, developing skills, and being fit were important benefits of participation in sports. M any girls reported that being part of a team was something they greatly valued. They expressed a sense of camaraderie, friendship, and belonging when they spoke of their teammates. Sisters with Talent, the name of one of the girls' teams, evokes an image of strong, talented young women working and playing together as family.

A 20-year-old member of the first female M YSA team observed: "If it were not for football I would not have met with my friends who are in M YSA." And a 15-year-old female football player expressed what belonging to a team meant to her: "Staying together as one team and not being on your own."

A common observation from girls was that being in MYSA provided them with structure and guidance and encouraged 


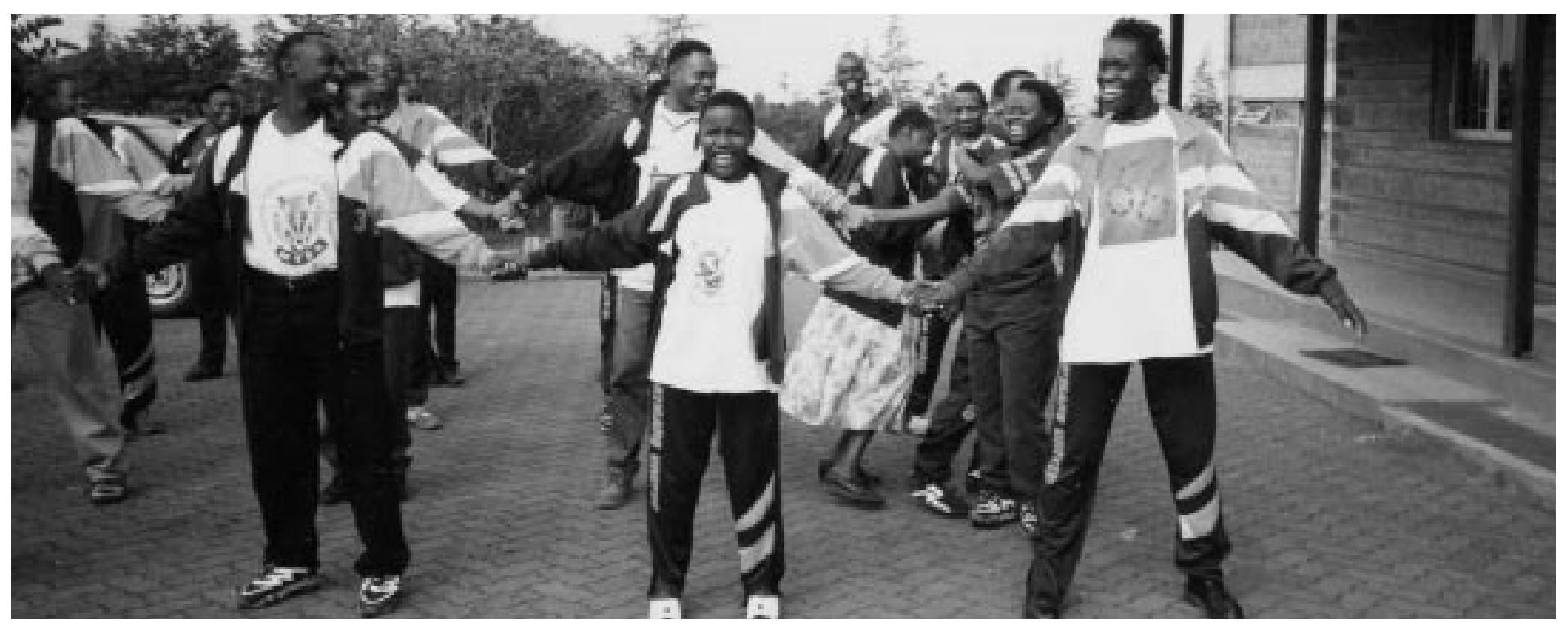

M ale and female participants in a team-building exercise at a gender training workshop.

healthy behaviors, as the following comments indicate:

I have learned how to have my own principles and not be blown and tossed around by the wind.

Before playing football I was fearful; now I am not because I am used to mixing with people, and I know what is good and what is bad.

[I havelearned] discipline- from home to the football field and vice versa so that you go and study at home.

Females are often defined in relation to others- as daughters, wives, and mothers rather than as individuals with unique personalities and talents. This is particularly true for young women. The emotional, psychological, and practical significance of having identification - in this case a passport- is impossible to quantify, yet it is clearly meaningful. $\mathrm{H}$ olding back tears of joy, one 13-year-old girl chosen to play in the N orway Youth Cup summed it up: "I have gained from being able to get a passport-now I am truly happy."

Education and learning. MSYA prides itself on its commitment to education for its members and their families. A 14-year-old football player remarked:

The scholarship that I won helped

to pay for my sister's tuition fee.

$\mathrm{N}$ ot only does M YSA strive to help its members remain in school, it also recognizes the importance of nonformal education. Given the alarmingly high rates of HIV infection in Kenya, M YSA's most important educational activity is its HIV/AIDS work. M any girls mentioned that the most important information they learned through M YSA was about AIDS and how they can protect themselves:

I have learned about drugs and diseases like AIDS.

Understanding the disease, how to pre vent yourself from getting it.

I learned about AIDS through the training, and now I formed a group that I give advice to.

L eadership and skill-building opportunities. Skill building and leadership development are important avenues for personal and professional growth for M YSA members. Selected girls have received specialized training and 


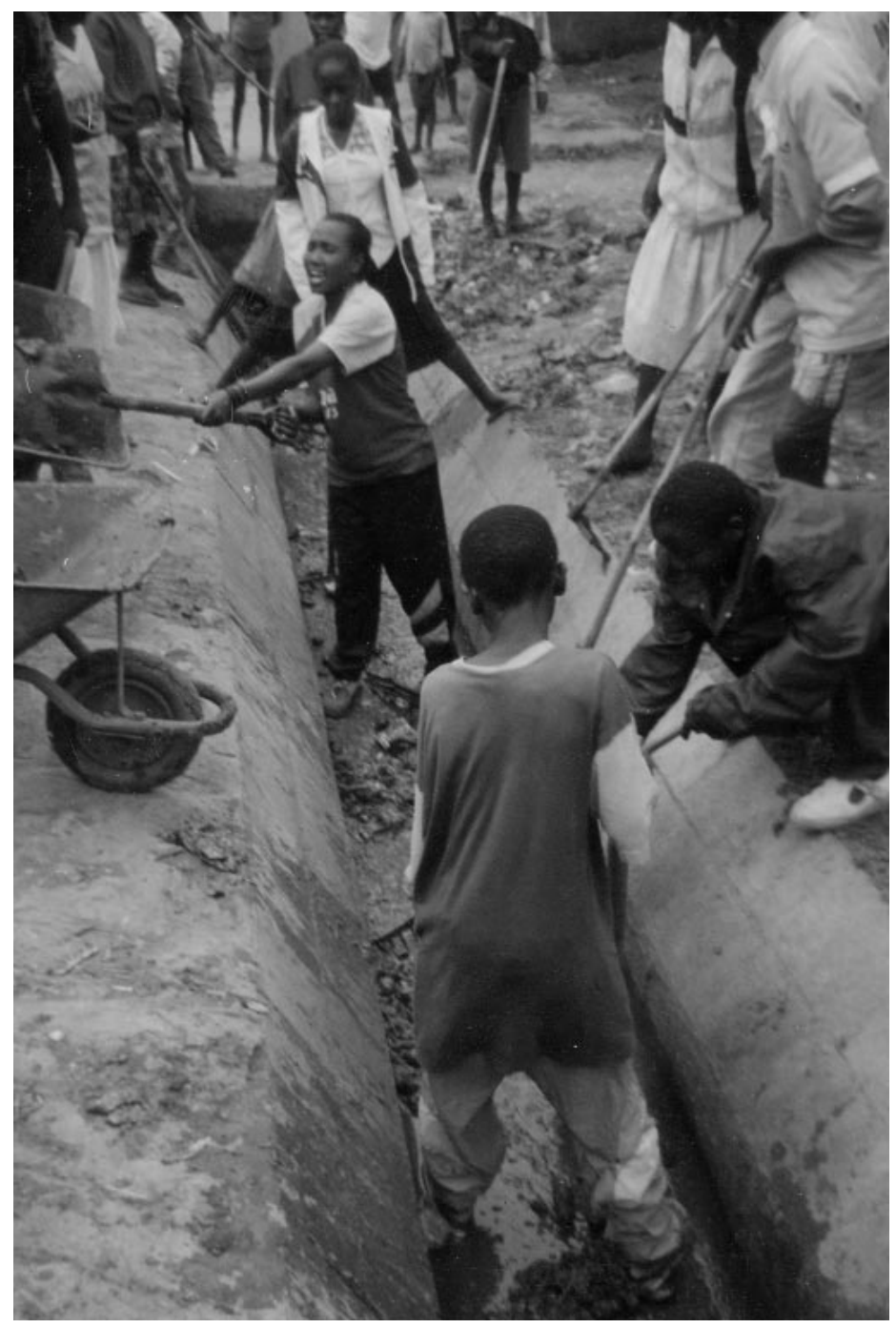

M YSA youth working together to clean up their community.

skills development in several areas, including peer education, facilitation, outreach, and coaching. Although boys outnumber girls in almost all training efforts and leadership skillbuilding programs, an increasing number of girls are beginning to participate in these activities. Girls who received specialized training were delighted with the opportunity and the new skills they acquired. They remarked on how much they had learned through MYSA:

I learned how to coach, how to officiate a match- that is, to referee - and to facilitate a workshop.
I never thought that I was going to learn to the extent that I would be able to coach and have my own team. But now I identify with my own team and I feel happy about it.

I have learned many things, especially from the counseling session that we attend. We have learned a lot and we use this to counsel kids on the dangers of drugs, glue sniffing, and other vices when they come for our drama shows on Saturdays.

Escaping the confines of daily routines. Girls' desires to have a life beyond the repressive and limited routines of their daily existence were illustrated in different ways. Girls frequently mentioned being "idle" or "idling," a notion that appeared contradictory in light of the significant domestic workload they carry. As an 18-year-old girl remarked:

I do chores in the morning before leaving the house because those who come after me are boys and still young. I wakeup as early as 5:00 a.m. to clean, wash clothes, and prepare lunch before going for practice to avoid trouble with my parents.

\section{A 16-year-old girl observed:}

At the moment I do a lot because my brother is the old-fashioned type who doesn't do anything in the house. We [she and her sisters] do everything for him. When I was in standard 5, I learned how to cook but our second last born [next to youngest] now is in standard 7 and he doesn't do much. Mom spoils him and I don't like it.

In the context of these girls' lives, "idleness" referred to having nothing interesting to do, not to having nothing to do. For example, while many girls mentioned that they were responsible for cleaning cooking utensils, doing the wash, and cooking, they felt they were "idling" when they were doing these bor- 
ing, repetitive tasks. The term "idle" was also used to describe individuals who were neither in school nor employed.

$M$ any girls expressed a desire to escape the tedium of their daily lives. For them, playing sports provided access to the dynamic, actionoriented world typically reserved for boys. Engaging in new activities also meant traveling to new venues.

Mobility and safety. While girls did not explicitly say that they feared for their safety, many alluded to the fact that they needed to be smart about where they went and how they conducted themselves in the community. Almost all mentioned that safety was a major concern of their parents and that they tried to get home on time in order to avoid punishment; being late could result in having to give up football. Girls spoke about having to ignore the taunts and jeers of the boys who teased them as they walked in the community, and there was general awareness of the potential dangers that surrounded them. Some remarked on how vigilant they must be in order not to "allow" themselves "to be tricked." O ne girl spoke of how she had to quit M YSA because of her fathers' concerns about her safety:

I left barely two months after I joined because the playground we were using wasa bit risky. It was next to a dumping field and there used to be many chokoras [street boys]. Sometimes we would finish the game late and we would risk being harassed by these chokoras. M y dad said if we couldn't get an alternative field, then I should quit. I tried convincing him that we are usually accompanied by boys from our zone but he wasn't convinced. It wasn't until we got an alternative field at Tom M boya that my dad allowed us to resume.

Given the concerns about safety and mobility in public space, girls had to devise strategies for dealing both with their parents'

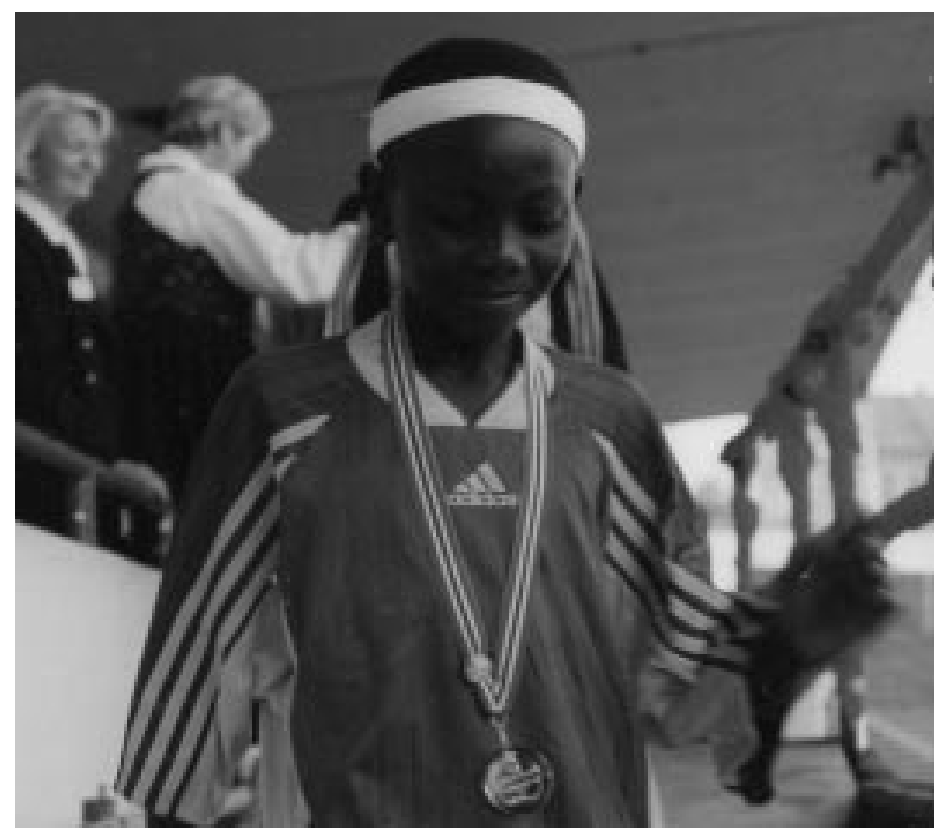

A girls' team member beams after winning a medal in competition as a crowd of international spectators applaud.

concerns and the dangers they faced. 0 ne step the girls took was to bring the issue of safety to the attention of MYSA management, which eventually resulted in concrete program changes (such as changing playing fields) to ameliorate the situation.

Public recognition and the Norway experience. As mentioned previously, wearing the M YSA jersey signals affiliation with a valued institution; the jersey is a source of both pride and protection for girls. Moreover it provides girls with a public identity-something many young women in $M$ athare do not have. This valued public identity seems to provide girls with a greatly needed sense of self-worth.

Another way that girls gain a positive identity is through participation in events in the larger world. The N orway Youth Cup provides girls with an opportunity to compete on an international level, meet girls from other parts of the world, and experience other cultures. G irls spoke positively about their experiences at the N orway Youth Cup; for many it 


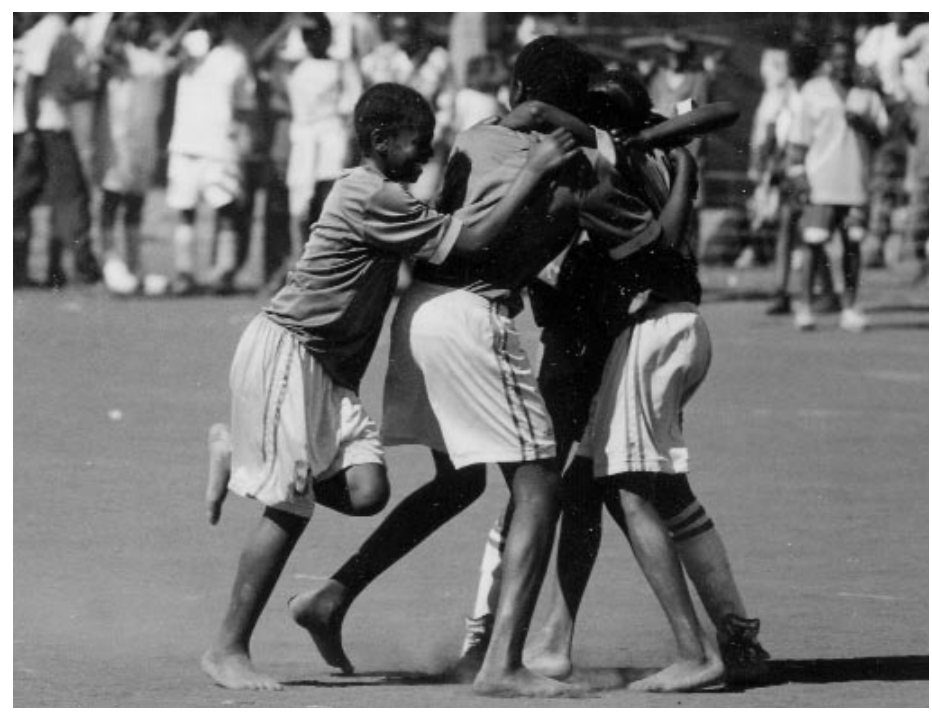

Solidarity, teammates, and friends: Girls share in the exhilaration of a goal!

was a life-changing event. They were proud of their accomplishments, they were happy to represent M YSA at an international event, and they were thrilled to meet girls from around the world. $M$ any remarked on the beauty and cleanliness of Norway and the generosity of their hosts, who gave them gifts of clothes and money. ${ }^{3}$ O ne 21-year-old player said:

It was quite an experience for me I had never dreamed of flying in an airplane, and herel wastouring a foreign country.

A member of M YSA staff said:

I was exposed to a different culture and a different way of life.

Given the size of the organization, the chance that an individual will be selected to participate in the Norway Youth Cup is quite low. Regardless, many girls pin their hopes on being chosen, and, in fact, the possibility of being chosen to participate in the Norway Youth Cup motivates many girls to join M YSA. Stories circulate about how after the
N orway selection process is over, some of those who didn't make it "cry for a week" and then quit. How the N orway Youth Cup should feature in M YSA's overall program is the subject of some discussion. Despite these concerns, however, the experience of competing internationally is an important feature of MYSA's football program.

Gender dynamics in the coaching process. Coaches have enormous influence over athletes and play multiple roles in a player's life. Abuse of power by coaches and issues of verbal, physical, and sexual harassment have plagued the sports community at large. Today, ethical codes of conduct for coaching exist, and coaching programs include training on how to identify and combat harassment. Given the centrality of this issue in sports, we wanted to understand girls' attitudes and perceptions of male and female coaches. D o girls have gender preferences regarding their coaches? W hat experiences have led them to have these preferences?

Girls indicated the qualities of a good coach: The person should be knowledgeable, should exercise good and fair judgment, and should be physically fit. The sex of the coach was not an important criterion for them, and they acknowledged that girls could theoretically do the job as well as boys with the right training, mentoring, and leadership opportunities. As one U 18 female football player summed it up: "I don't prefer a man or women as long as they do the job."

N onetheless, in practice, when girls were asked if they preferred a male or female coach, the majority of girls responded that they preferred a male coach. To some degree, this seems to reflect the perception that boys have

${ }^{3}$ In addition to providing partial funding for M YSA students' school fees, N orwegian support has been instrumental in the development and expansion of the girls' program. A scholarship program has recently been created to provide funds to pay school fees for a select number of M YSA youth. 
more experience with sports and have greater coaching expertise. H owever, some of the preference for male coaching reflects a deference to male authority. Some girls even mentioned that they would not respect a female coach. General comments included:

They [boys] know how to handle girls.

They take care of you.

He always gives us bus money and he buys us lunch.

When asked if she thought the male coach paid for lunch with his own money, one girl responded, "O h yes, it comes from his pocket."

In reality, the money came out of his pocket but not from his pocket. MYSA provides coaches with a small amount of money to pay for lunches and beverages when the team is playing a match or is training at a location far from home. This misperception illustrates girls' economic powerlessness and their dependence on boys, situations that could result in male coaches being in a position to abuse their authority.

A range of issues emerged from the discussion of coaching, including the need for girls to have more opportunities for training and skills development. MYSA has begun tackling the gender disparity in coaching and leadership. It is noteworthy that the issues raised here are not unlike those found in developed-country settings as well. The need to address gender imbalances in coaching and leadership opportunities appears to be a universal theme.

Fairness between boys and girls. The notion of fairness and equity came up in different ways for males and females. $M$ any of the girls felt that boys were given priority in several areas. For example, girls mentioned that boys had more opportunities and that boys had access to the best playing fields and hours for practice and to better equipment and coaches.
Girls felt they had to "adjust" to the boys' schedules and use of playing fields. O ne U 18 female football player said:

If, for instance, there are different tournaments for boys and girls at the same time, they will give first priority to the boys.

Another observed:

What I see is that girls are not given opportunities to hold on to. They are given those low things, You have to sweet talk them [boys] and they ask for favors from you.

$M$ indful of the relatively high levels of sexual coercion among girls in Kenya, girls were asked to elaborate on some of the risks and pressures they faced. In one such case an 18year-old girl explicitly identified sexual favors as an issue:

Some [girls] are ignorant, and the desperation leads them to agreeing to this favor, but those learned ones [girls] dis. agree and this leads to mistreatment and disagreements.

The degree to which girls are exploited or coerced into providing sexual favors within MYSA is not known, yet within the larger community young women- particularly economically vulnerable young women- often find themselves in such circumstances.

Another area in which the question of fairness and equity arose concerned the workload of MYSA members and staff. The daily operations in an organization of M YSA's size require that numerous tasks be carried out. The division of labor to accomplish these tasks broke down along gender lines. For example, girls initially were responsible for washing all of the football jerseys, which numbered several thousand, and for tidying up the offices. Boys handled the sports equipment and did maintenance chores. Boys drove the garbage clean-up trucks while girls took care of the younger 
siblings of M YSA players. The gender breakdown of domestic chores typically found at home had been transferred to M YSA.

It is heartening that after a series of gender awareness workshops, staff have come to recognize the stereotypic work roles they have created within the organization. M YSA's response is detailed in a subsequent section.

\section{H ow G irls Experience Boys' Reactions to Their Participation}

It is difficult for adolescent females to take on new roles and enter into the public sphere without support from boys and freedom from harassment. Boys' opinions are not the only impediment, however. Girls' perceptions of their self-worth are critical, as is their developing a sense of entitlement regarding active participation in society.

When girls were asked what they liked and disliked about M YSA boys, their responses were mixed and complex. Girls had a number of complaints about boys' behavior:

They take our ball and throw it away intentionally.

When you go for training and you miss something small, the boy can insult you and this might stop you from playing.

Sometimes they like inciting us and they throw stones at us. Then we tell the coach and he stops it.

Sometimes when a girl is pressed [has to urinate] and she goes to the toilet, boys come to peep.

While such behavior on the part of boys is worrisome and warrants attention, the simple fact that girls are able to recognize bad male behavior and voice a strong opinion about it reflects progress toward girls' recognizing their own value. $O$ ne girl observed, "N owadays girls don't like boys because they insult them, and girls hate that."

Such sentiments may indicate that girls' notions of what constitutes appropriate treatment by boys are beginning to change. Girls may be starting to want and expect more egalitarian relationships with male peers. Participation in M YSA may be helping girls develop a greater sense of self-worth and providing them with a forum in which to discuss issues of importance to them. It is interesting to note that when girls were asked to reflect on their future, many said they wanted different kinds of marriages than those their mothers had: They wanted more equal partnerships. Further they stated that they wanted their daughters to have greater opportunities than they themselves had. Such sentiments corroborate what research suggests: Investments in young women translate into both changed aspirations for their children as well as changes in the ability of young women to deliver on those aspirations.

D espite some of the negative feelings and comments girls expressed, it is noteworthy that many girls viewed MYSA boys positively in comparison to boys outside of M YSA. In general, girls expressed a sense of feeling protected by MYSA boys. For example, when people from outside of MYSA pick fights with M YSA girls, the M YSA boys come to their defense.

There is a big difference, for example in their [MYSA boys'] conduct; their behaviors are very respectful. They do not abuse each other. Thisis because they have been taught how to be disciplined.

What I like about them [boys] isthat they are the ones who taught girls football.

Boyś Perspectives on Girls Participation in M YSA

Despite their initial skepticism about girls' physical abilities, particularly regarding foot- 
ball, boys have come to see that girls are capable players. Although boys spoke in terms of girls' ability to "play football," their remarks may refer to capacities beyond that. Seeing girls achieve success in what had been a male domain may begin to reshape boys' notions about girls' roles and capabilities. At this stage in MYSA's evolution, most boys view the inclusion of girls in M YSA as positive. M any feel it is important that boys and girls learn to work and play together.

While most boys felt that boys and girls were treated evenly and fairly within M YSA, some felt that girls were given preferential treatment; for example, some boys felt that girls didn't have to train as hard as boys, were given easier jobs, and generally were not "as serious" as boys. In general boys felt that girls were harder to teach and did not learn as quickly as they did. This view was most often expressed in relation to coaching. The notion that boys were better able to "handle" girls was also voiced. Some boys were simultaneously empathetic and patronizing, as illustrated by the following remark from a male coach:

In my coaching of girls and being with girls for a long time, I found that you have to be very patient with them. They are fragile and give up easily. They need a lot of love so you have to be committed and very patient with them.

A number of boys said they felt protective of M YSA girls and would try to "watch out" for them in the community. M ost boys reported treating M YSA girls "like family." T his combination of genuine concern on the one hand and patronizing, and often sexist, behavior on the other is not uncommon. The challenge for girls is both philosophical and pragmatic: To what extent should girls seek ways to maneuver within this framework versus make efforts to change male behavior?

It is important to recognize the differing perceptions and beliefs held by boys and girls

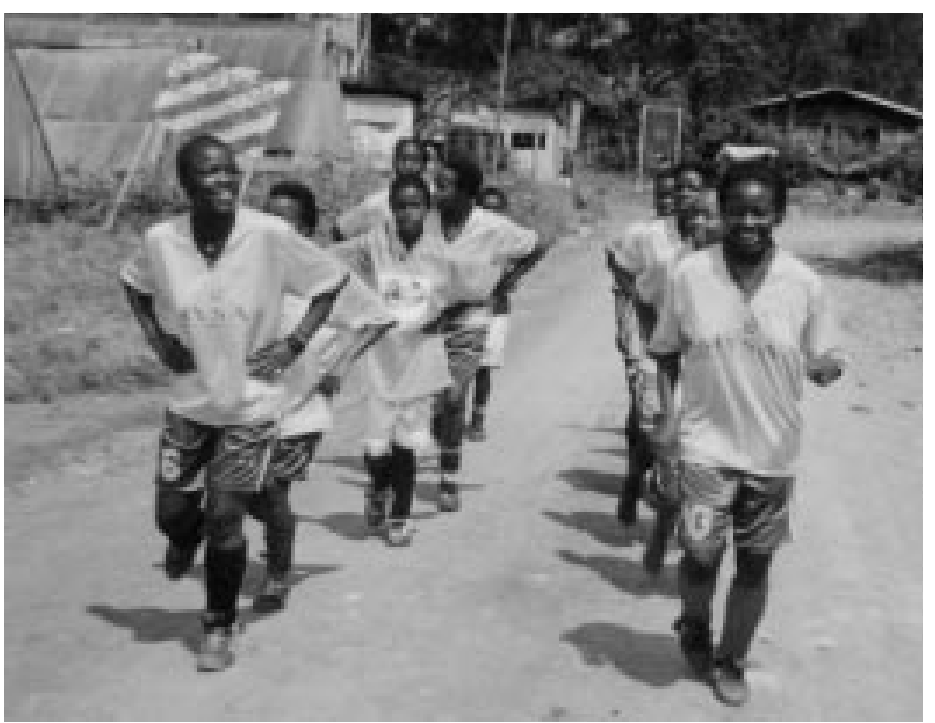

A girls' team in training, jogging in a group through the community.

on issues ranging from equity in treatment to gender roles. An awareness and acknowledgment of these differences by program managers is an important step in any effort to address them programmatically.

\section{H ow M YSA Responds to Girls Concerns: Institutional and Program Changes}

There are numerous and complex issues that arise for girls in MYSA's mixed-sex setting. Solutions to some of these problems require philosophical and institution- and programlevel changes. Because MYSA is a dynamic organization, it continually seeks ways to overcome the challenges it faces. It reflects upon its work, considers the views of its members, and develops strategies and processes for addressing problems.

O rganizationally, M YSA operates through a system of councils and committees responsible for key program areas. There is a sports council, a community services council, and an executive council. These councils provide structure and serve as decisionmaking bodies 
for the organization. It is through the various councils and committees that issues are raised. Initially these councils were composed exclusively of boys; however, as M YSA has evolved, a deliberate effort has been undertaken to bring girls into organizational decisionmaking. Currently, at least one girl is appointed to each of the councils. Interestingly the community service council, which has jurisdiction over the garbage clean-up efforts, consists of all girls with the exception of one boy, while the sports council is composed of all boys with the exception of one girl. It is likely that this gender composition will change over time.

\section{Girls' Task Force}

In order to address some of the concerns arising in the girls' program, a girls' task force was created in 1999. Although its mandate was broad, it focused initially on investigating the drop in girls' enrollment, particularly within the older age groups, and reports of girls being harassed within and outside of MYSA. Enrollment was dropping for many reasons, including, but not limited to, safety, parental concerns, preferential treatment of boys, and comparatively few opportunities for girls' development and advancement. The task force was not established as a permanent body - it was set up to explore a particular set of issues. The task force did its work, issued a report, and helped bring to the attention of M YSA's leadership some of the challenges girls were facing. Although it is no longer operating, the fact that M YSA set up a task force at all is an indication of its commitment to girls' involvement.

\section{Addressing Safety Concerns}

Because safety and mobility issues emerged as a chief concern of girls and their parents, a few key programmatic changes were put in place. For example, the scheduling and hours of girls' training and matches and the locations of play- ing fields were modified to ensure girls' safety. Girls are sometimes provided with a small transportation allowance so that they can travel to and from playing fields more easily and safely. In addition, when girls attend MYSA staff and/or organizational meetings they are permitted to leave early - before dark - so that they can reach their destinations before nightfall.

When the first girls team traveled to $N$ orway to play in the N orway Youth Cup, the executive council of M YSA- in recognition of the fact that both the female players and their male coaches were young and inexperiencedcreated a chaperone policy that provided for a trusted adult female from the community to serve as a mother figure for the girls. Female chaperones offer guidance and support to the girls, and their presence helps allay the concerns of parents. This policy remains in place today.

In 1999, the former chief executive officer of MYSA made the following statement that recognizes the obstacles girls face- particularly concerning safety- and sums up some of the accommodations that have been made:

My feeling is that girls no matter how old they are- be they wives - they still need a lot of care Their problems need to be addressed and especially in an organization like M YSA where we have many girls, we had to bend some of the rules regarding girls... Like in our meetings, if a girl is lected in a leadership position, another girl can accompany her, just for her own security. But for a boy, if you area representative of a council and you are coming from a faraway zone, you just come alone. But for girlswe can even provide transport.

\section{Rethinking Gender Roles and N orms}

Recognizing the need to enhance gender equity, M YSA embarked on a gender partnership 
project, which consisted of a series of gender training workshops for key MYSA staff and selected males and females within the organization. The project was effective in raising aware ness of gender issues in general and in highlighting specific examples of gender stereotyping that were at work within the organization. O ne outcome of these workshops was a concerted effort to restructure the division of labor within the organization. For example, doing the laundry-formerly a "girls' job" - is now shared by MYSA boys and girls. Boys now wash football jerseys, and girls can be seen driving garbage clean-up trucks. The care of younger MYSA siblings, which had long been considered girls' work and was a major impediment to girls' participation, was also restructured. M YSA devised a strategy that provided for alternative child-care arrangements; tents were set up near the football fields to serve as childcare centers during matches and tournaments. These childcare centers were jointly staffed by M YSA girls and boys. The tents also provided needed shade and served as first aid stations. Such a creative approach to problemsolving is one of M YSA's strengths.

\section{D eveloping Female Leaders}

In recent years MYSA has made efforts to develop leadership capacity among selected female members. A leadership training program for boys and girls has been established that aims to create a cadre of leaders who will eventually organize and run the girls' football program. Training is provided in key life skills such as communication, decisionmaking, team building, group dynamics, and conflict resolution. A coaching and referee training program was also established in which increasing numbers of girls now participate. Several girls have risen through the ranks of MYSA to take on leadership positions as project managers, coaches, and referees. Today - some ten years

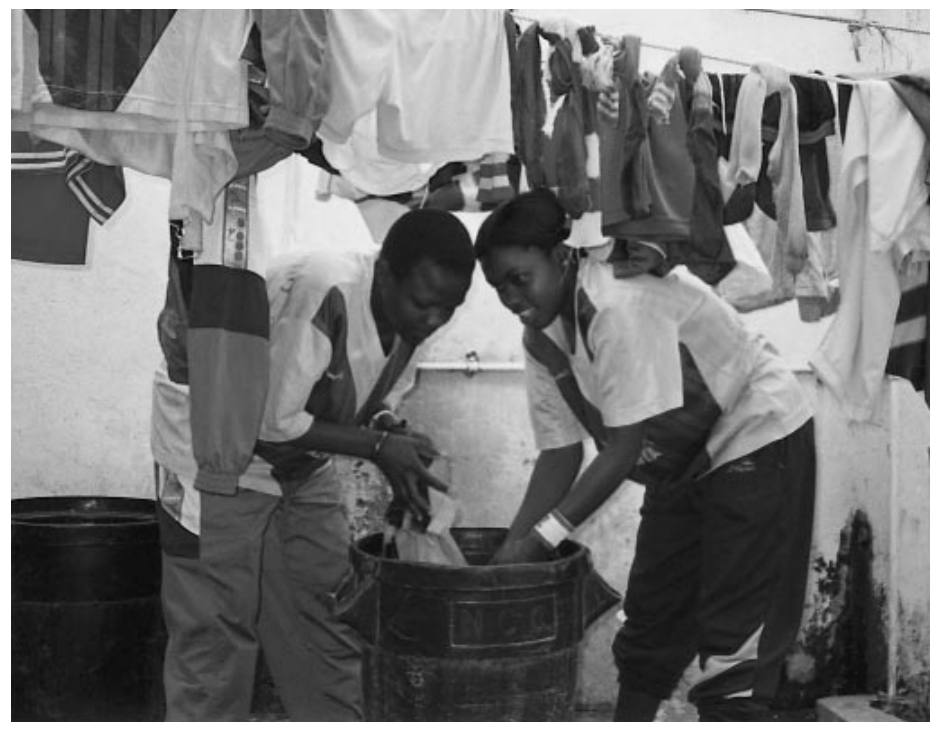

Washing the thousands of M YSA jerseys is no longer seen as "girls work." Boys and girls now share the workload.

since the beginning of the girls programM YSA has hired a female coordinator to lead the girls' football program. This is a significant achievement.

While a great deal of progress has been made, more work is needed in all of these areas. There is little doubt that MYSA will continue to define problems and seek novel solutions.

\section{D rawing Lessons from M YSA's Experience to Inform Program D esign}

Effective programs are built upon good ideas and a solid understanding of the prevailing norms and beliefs in the communities in which programs will operate. 0 ur research and experience suggest that there are several critical issues program planners need to address as they develop programs for girls. While recognizing the diversity and uniqueness of different regions and the context-specific nature of programming within countries, certain universal themes resonate in most settings. We offer these guiding principles to help program planners develop successful programs for girls. 


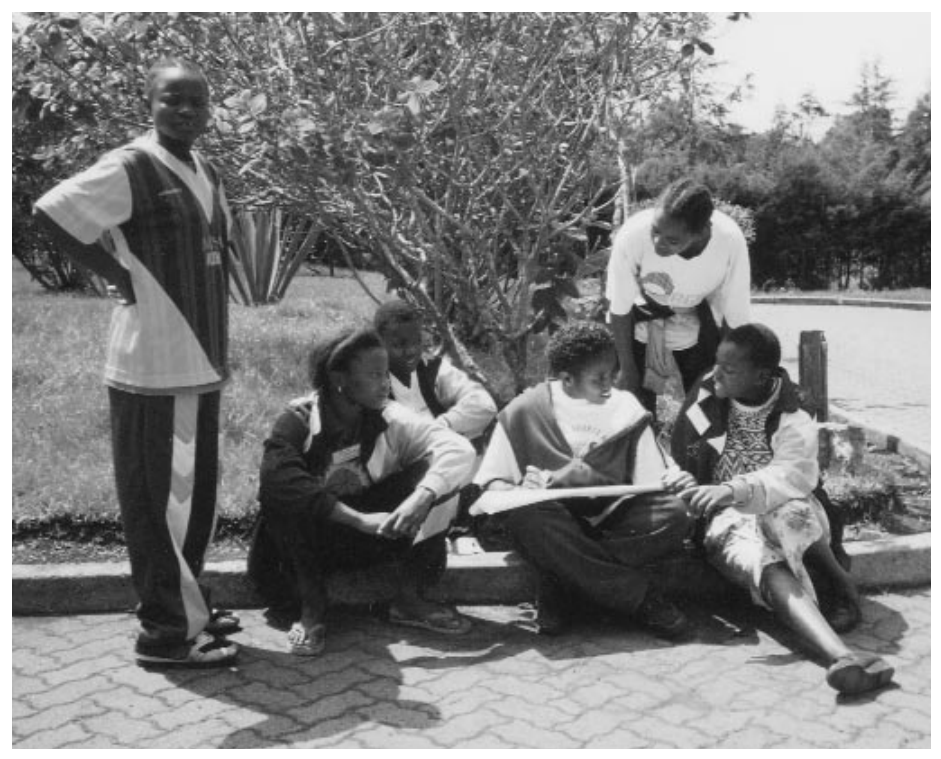

Female leaders planning workshops and skills training.

D efining the Program's Philosophy and Goals

At the outset of any program planning, the overall goals and philosophy of the program must be defined. In this regard, some overarching questions to consider might include:

- Is gender equity articulated as a program goal? How so? W hat efforts are made to implement that goal?

- Are there equal opportunities for boys and girls in terms of number of matches, training sessions, educational events, travel possibilities, workshops, and so forth?

- Are there specific guidelines regarding conduct and codes of behavior for boys and girls? Are these guidelines enforced?

- Are there appropriate role models (including coaches, referees, and so forth) for girls?

- Are certain activities stereotypically deemed male or female?

-W hat implicit or explicit messages do girls receive when they get out on the playing field? When they read the organizational literature (eg., posters, brochures)?
D etermining Program Content

A multifaceted program that attempts to address the broad needs of girls may be more successful in attracting and retaining girlsand may prove more acceptable to parents and community leaders- than one that is focused solely on sports. For example, programs that have a community service or educational component are likely to gain community and parental support. M oreover, such holistic programs may provide a natural environment in which basic reproductive health information and links to health services can be provided.

\section{Getting Girls to Partici pate: Recruitment}

Evidence from a variety of settings suggests that girls want to participate in new activities and programs. However, accommodations must be made in girls' lives and programs regarding scheduling, domestic responsibilities, and mobility if a program is serious about serving girls. Strategies to attract girls must be informed by a solid understanding of the factors that impede or permit their participation. A strong outreach effort focused on girls and their parents is needed, and recruitment strategies must go beyond initial outreach and a one-time-only approach.

Retaining Girls in Programs:

Setting the Terms of Participation

O nce enrolled, programs must ensure that girls' voices are heard and their needs met in order to ensure their continued participation. Program planners must set realistic goals in terms of the degree and length of participation one might reasonably expect of girls in a given community. Planners need to be flexible in setting the terms of participation, allowing girls to enter or reenter programs easily (to the extent that this is logistically possible and not disruptive to other participants). Finally, enlisting the help of parents and community leaders is critical to 
ensuring that girls are able to participate to the maximum extent possible so that they can reap the intended benefits of the program.

I dentifying M easures to K eep G irls Safe and Protect Their Reputations

Enabling girls to enjoy greater freedom of movement and participation in community life, while at the same time maintaining their safety and dignity, is one of the most complex and socially significant challenges programs face. Some simple measures can be taken to increase the safety of program participants. For example, program planners should ensure that girls' matches are played before dusk, that appropriate arrangements are made for transport, and that appropriate escorting/chaperoning procedures (femaleled rather than maleled) are in place. Teaching girls to recognize potentially dangerous situations is another way to ensure their safety. O ne way to approach this is with a community mapping exercise in which girls highlight safe and unsafe areas of their community. Another technique is to teach girls how to "walk big" and "walk with a purpose" so that they will not be seen as vulnerable. Finally, girls should be taught to stay in groups, which is an extremely effective strategy to ensure safety.

Offering Girls Female M entors and Role M odels

Girls' support systems within and outside of organizations must be improved. It is essential that trusted female role models and leaders from the community be identified and asked to serve as mentors and advisors to girls. These individuals should be aware of the challenges that girls face and be willing and able to act as advocates on their behalf. 0 ver time, as girls grow more confident in their environment and begin to trust these individuals, they will turn to them for guidance and assistance in problem-solving. Girls will seek information on a wide range of topics. Programs should give

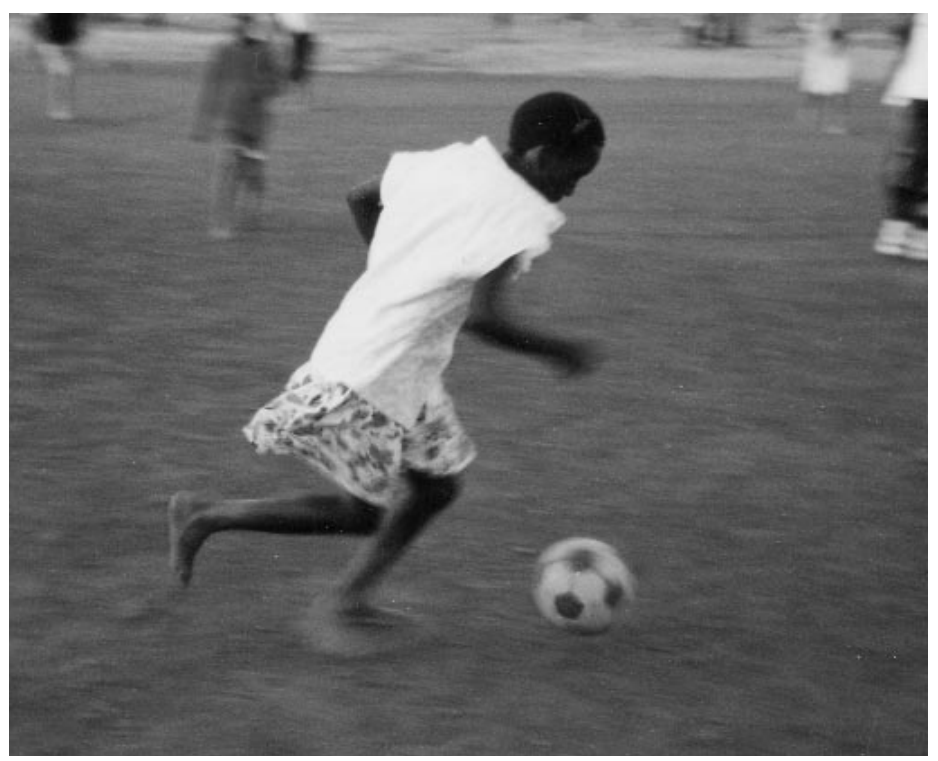

The sheer joy of movement: A moment of total freedom.

serious consideration to identifying, attracting, and training female mentors and role models.

\section{Encouraging Girls Self-Expression, D ecisionmaking, and Leadership}

Evidence from a variety of settings suggests that when boys are present, girls adjust the roles they play, anticipating the reactions they have come to expect from boys and adults. Whether consciously or not, girls may become inhibited or may retreat from, or avoid, situations that involve physically or verbally aggressive boys. This pattern for girls seems to hold true even when girls are in the majority, and even more so when they are in the minority. Girls who might be leaders in girls-only settings may not feel comfortable with a leadership role in a mixed-sex setting. Thus if possible, creating single-sex activities and/or designated girlsonly spaces would be beneficial for girls.

Bringing young women into the ranks of leadership and preparing them to take on leadership roles is a challenge for many organizations. D oing so requires concerted effort and human and financial commitment. And while there is no formula for accomplishing this, 


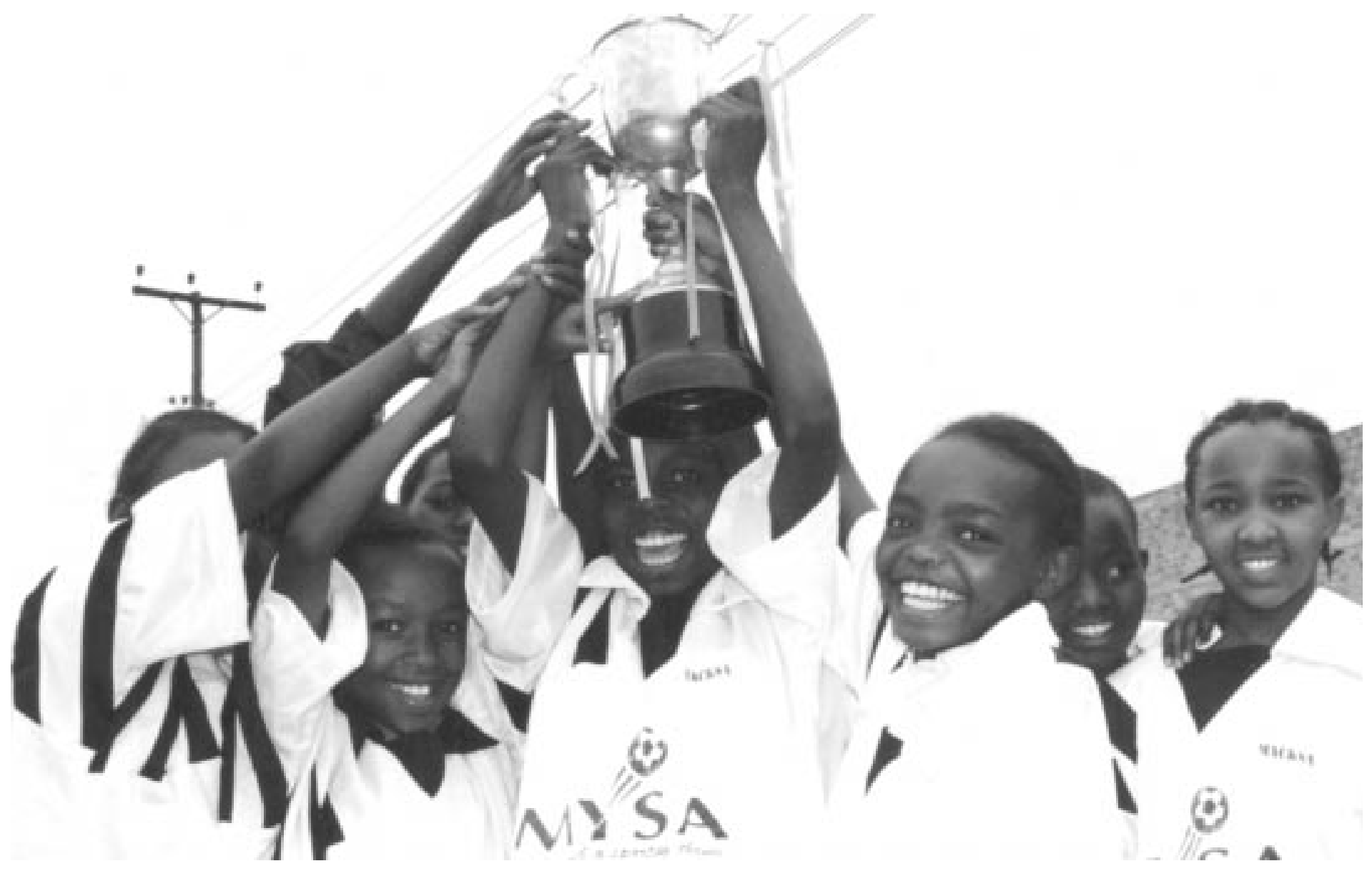

The thrill of victory!

there are some key elements for success. Identifying talented girls with leadership potential is a first step. Providing girls with a supportive and collaborative environment that enables them to build on current skills and knowledge while practicing and developing new skills is critical. Finally, girls' experience and talents must be validated and their accomplishments celebrated.

\section{Encouraging Boys to Be M ore Respectful}

Building girls' skills and sense of agency will go only so far if girls find themselves in the same restrictive environments. Boys are particularly important in this regard as their behavior in public spaces and in the home bears strongly on girls' mobility and participation in public life, and because boys are the future husbands and partners of the girls programs hope to reach.

Serving girls better through thoughtful and sensitive programming not only benefits girls but the larger society as well. Valuing girls is good for girls and also for communities. When they see girls in new roles, boys can learn about the strengths, capabilities, and contributions of girls and women, which may begin to reshape their perceptions of females. Transforming gender norms may help decrease the pressure many boys feel to conform to traditional roles, behaviors, and ways of thinking. In short, empowering girls may help to enlighten boys. 


\section{Some Final T houghts}

From its modest beginnings the $M$ athare Youth Sports Association has grown into a complex, multifaceted youth-serving organization- one of the largest in Kenya. M YSA has been a pioneer in many respects. It has been on the forefront in defining the links between youth development and environmental issues in sub-Saharan Africa, and it has been one of the only youth sports organizations in Africa that has encouraged girls' participation. Today the organization serves both boys and girls and the $M$ athare community more generally; its members number in the thousands. 0 ver the years M YSA has received international recognition and acclaim for its vision and reach. Through its efforts we have begun to see how sports can serve as an entry point for social development and for the transformation of gender norms.

M YSA began simply, yet over the years it has refined its goals and programs in response to the changing needs and interests of the community it serves - a testament to its institutional resiliency. Today it faces what could be one of its most significant social and institu- tional challenges, that is, how to address gender equity within the organization and its programs. To ensure that girls find their rightful place within the organization, a further analysis of the institutional barriers to gender equity is needed. Carrying out such analysis will lead to a deeper understanding of how patterns of behavior within the organization may be welcoming or inhospitable to girls. Improving girls' opportunities and outcomes goes beyond simply increasing their participation in programs and activities. It goes to the very heart of the organization, including not only its mission and philosophy, but also how its staff think and act, their background and training, and their perspectives on girls' roles.

While the task of transforming MYSA into a truly gender-equitable organization is enormous, there is little doubt that M YSA will tackle this challenge with the same resolve, creativity, and entrepreneurial spirit that have brought it to where it is today. Goal setting and hard work have long been guiding principles for M YSA. This process will undoubtedly continue. In the words of one of its mottoes, "Haba na haba hujaza kibaba," or "Step by step we reach the goal." 


\section{Appendix: Gathering Information for this C ase Study}

The Population Council carried out a qualitative study to learn about the organizational structure and style of the Mathare Youth Sports Association, the content and scope of its programs, and the experience and perspectives of the young women and men who are part of the organization. We were particularly interested in understanding girls' experiences - the nature and intensity of their participation, the challenges they face, and how these challenges were handled. M oreover, we wanted to learn directly from girls what participation has meant for them.

We used a combination of data sources, including program documents, press articles, existing program "service" statistics, in-depth interviews, and focus-group discussions. In addition, we had considerable interaction with staff and made numerous site visits and direct observations of program operations.
We met with staff to review record-keeping systems and to obtain pertinent program statistics. In-depth interviews were conducted with key program staff, the resident chief executive officer, members of the girls' task force, parents, and girls 10-18 years old. We interviewed girls from high-, medium-, and low-participating catchment areas or "zones" (participation is defined by the number of teams and matches played in a particular zone) in approximately equal numbers. In addition, a group discussion was held with the girls from the only existing U 18 girls team. Finally, we conducted focusgroup discussions with boys ages 14-16.

A semistructured interview was applied to all respondents, and interviews were audiotaped and transcribed. Focus-group discussions with boys were conducted by a trained male researcher. D ata were codified and analyzed using qualitative data analysis techniques. 


\section{References}

"African charter on the rights and welfare of the child." 1990. Adopted by the twenty-sixth ordinary session of the assembly of heads of state and government of the O rganization of African Unity, Addis Ababa, Ethiopia, July.

Government of Kenya, M inistry of Planning and $N$ ational Development, Central Bureau of Statistics, and Long-Range Planning Unit. 1991. Rural Labor Force Survey, 1988/89.

H ake, Andrew. 1977. African M etropolis. Nairobi's Self-H elp City. N ew York: St. M artin's Press.

M ensch, Barbara S. and Cynthia B. Lloyd. 1998. "Gender differences in the schooling experiences of adolescents in low-income countries: The case of Kenya," Studies in Family Planning 29(2): 167-184.

$\mathrm{N}$ ational Council for Population and D evelopment (N CPD ), Central Bureau of Statistics (CBS) of the Office of the Vice President, Kenya Ministry of Planning and $N$ ational D evelopment, and M acro International. 1999. Kenya Demographic and Health Survey 1998. Calverton, MD: NCPD, CBS, and Macro International.

President's Council on Physical Fitness and Sports. 1997. Physical Activity and Sport in the Lives of Girls. Washington, DC: US Department of $H$ ealth and $H$ uman Services.
Sabo, D onald, Kathleen M iller, M ichael Farrell, Grace Barnes, and M errill M elnick. 1998. The Women's Sports Foundation Report: Sport and Teen Pregnancy. East M eadow, NY: Women's Sports Foundation.

Thompson, Sharon. 1995. Going All the Way: Teenage Girls Tales of Sex, Romance, and Pregnancy. N ew York: $\mathrm{H}$ ill and Wang.

United $\mathrm{N}$ ations Educational, Scientific, and Cultural O rganization (UNESCO). 1978. Preamble to International Charter of Physical Education and Sport. Adopted by the $\mathrm{G}$ eneral Conference at its twentieth session, Paris, 21 N ovember.

US Bureau of the Census. 2000. HIV/AIDS Surveillance Data Base. Washington, DC: Population Division, International Program Center.

World Health Organization (WHO). 1999. "Programming for adolescent health and development: Report of a W H O/U N FPA/U N ICEF study group on programming for adolescent health," WHO Technical Report Series no. 886. Geneva: WH O.

Zulu, Eliya M., Alex C. Ezeh, and F. Nii-Amoo Dodoo. 2000. "Slum residence and sexual outcomes: Early findings of causal linkages in Nairobi, Kenya," African Population and $\mathrm{H}$ ealth Research Center (APH RC) Working Paper no. 17. Nairobi: APH RC. 


\section{Suggested Reading}

American Association of University Women (AAUW) Educational Foundation. 1998. Separated by Sex: A Critical Look at Single-Sex Education for Girls. Washington, DC: AAU W Educational Foundation.

Barker, Gary. 2000. "Gender equitable boys in a gender inequitable world: Reflections from qualitative research and programme development in Rio de Janeiro," Sexual and Relationship Therapy 15(3): 263-282.

Brady, M artha. 2002. "A place of her own: Safe spaces for girls," UNFPA programme document. N ew York: U N FPA. Forthcoming.

- - . 1998. "Laying the foundation for girls' healthy futures: C an sports play a role?" Studies in Family Planning 29(1): 79-82.

"Brighton declaration on women and sport." 1994. Declaration endorsed by participants at the First International Conference on Women and Sport, Brighton, UK, 5-8 M ay.

Brockerhoff, Martin and Ellen Brennan. 1998. "T he poverty of cities in developing regions," Population and Development Review 24(1): 75-114.

Garvin, Alexander and G ayle Berens. 1997. U rban Parks and 0 pen Space. Washington, D C: U rban Land Institute.

Girls, Inc. 1993. "W hat's equal? Figuring out what works for girls in coed settings," monograph. Indianapolis: Girls Incorporated National Resource Center.

Jaffe, Lynn and Rebecca M anzer. 1992. "Girls' perspectives: Physical activity and self-esteem," M elpomene Journal 11(3): 14-28.

Lamba, Davinder. 1994. "The forgotten half: Environmental health in Nairobi's poverty areas," Environment and Urbanization 6(1): 164-173.

$M$ ensch, Barbara S., Judith Bruce, and M argaret $E$. Greene. 1998. The Uncharted Passage: Girl's Adolescence in the D eveloping World. N ew York: Population Council.

M ensch, Barbara S., Wesley H. Clark, Cynthia B. Lloyd, and Annabel S. Erulkar. 2001. "Premarital sex, schoolgirl pregnancy, and school quality in rural Kenya," Studies in Family Planning 32(4): 285-301.
M iller, Kathleen E., D onald F. Sabo, M ichael P. Farrell, Grace M. Barnes, and Merrill J. M elnick. 1998. "Athletic participation and sexual behavior: The different worlds of boys and girls," Journal of Health and Social Behavior 39(2): 108-123.

M itchell, Carolyn (ed). 1995. Gender Equity Through Physical Education and Sport. Reston, VA: American Alliance for $\mathrm{H}$ ealth, Physical Education, Recreation and $D$ ance.

$\mathrm{N}$ icholson, H.J. 1992. "Gender issues in youth development programs," working paper. N ew York: Carnegie Council on Adolescent D evelopment, Carnegie Corporation of $\mathrm{New}$ York.

O wens, W illis. 1999. "Sport and development: The significance of $M$ athare Youth Sports Association," paper presented at the Canadian Association of Studies in International Development Conference, Q uebec, Canada, June.

"Plan it safe: A guide for making public places safer for women," publication of the Safe Women Project, http://www.lawlink.nsw.gov.au/swp/ swp.nsf/pages/swp_intro, accessed 8 April 2002.

Population Council. 2000. "Girls and sports in East and Southern Africa," fact sheet. Nairobi, Kenya: Population Council.

Rao, Aruna, Rieky Stuart, and D avid Kelleher. 1999. Gender at Work: Organizational Change for Equality. West $\mathrm{H}$ artford, CT: Kumarian Press.

Rogow, Debbie. 2000. Alone You Are Nobody, Together We Float: The Manuela Ramos M ovement, Q uality/Calidad/Q ualité no. 10. N ew York: Population Council.

Sarin, M adhu. 1993. Wasteland Development and the Empowerment of Women: The SARTHI Experience, SEEDS no. 16. N ew York: Population Council.

United Nations International Conference on Population and Development. 1994. Programme of Action. New York: United Nations.

Women's Sports Foundation Web site. 2002. http://www.womenssportsfoundation.org. 


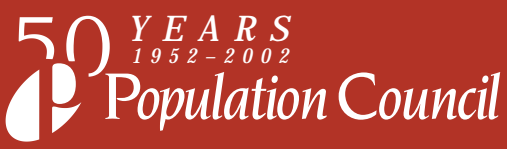

O ne Dag H ammarskjold Plaza

New York, New York 10017

www.popcouncil.org 